\title{
Engineering and Physics Optimization of Breed and Burn Fast Reactor Systems - Annual and Final Report
}

NERI Project No. 2002-05

Theron Marshall James Parry Kevan D. Weaver

October 2005

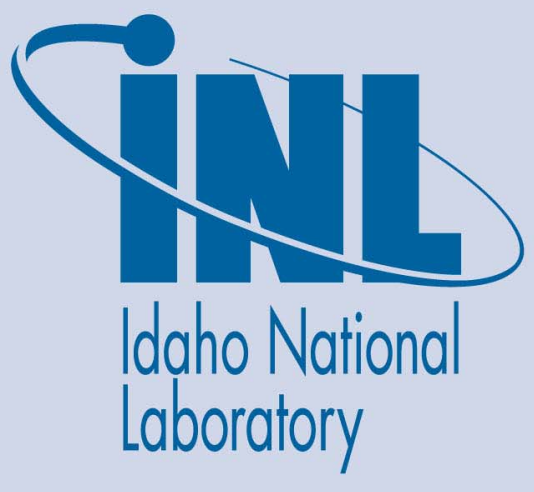

The INL is a U.S. Department of Energy National Laboratory operated by Battelle Energy Alliance 
INL/EXT-05-00886

\section{Engineering and Physics Optimization of Breed and Burn Fast Reactor Systems - Annual and Final Report}

NERI Project No. 2002-05

Theron Marshall

James Parry

Kevan D. Weaver

October 2005

Idaho National Laboratory

Idaho Falls, Idaho 83415

Prepared for the

U.S. Department of Energy

Under DOE Idaho Operations Office

Contract DE-AC07-05ID14517 


\section{Table of Contents}

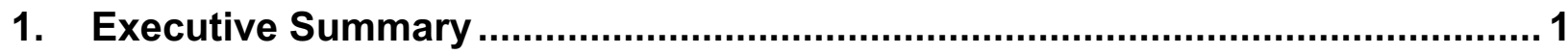

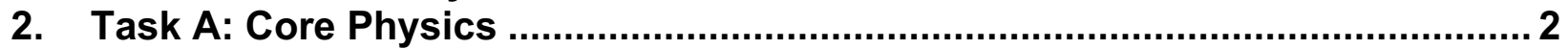

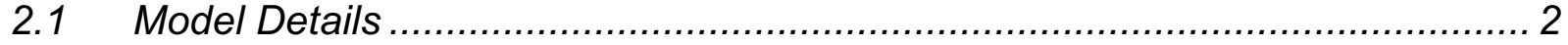

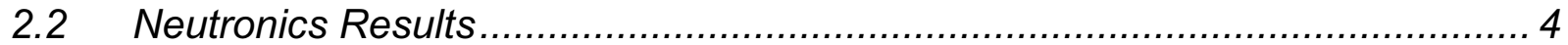

2.3 Plutonium Fueled Depletion Model .......................................................... 7

$2.4 \quad$ 14\% Enriched Uranium Fueled Depletion Model ....................................... 12

$2.5 \quad 7 \%$ Enriched Uranium Fueled Depletion Model .......................................... 16

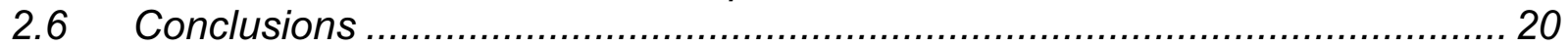

3. Tasks B and C: Core Thermal Hydraulics and Plant Design ..........................21

3.1 Fundamentals of the Design ............................................................. 21

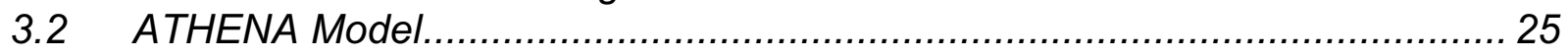

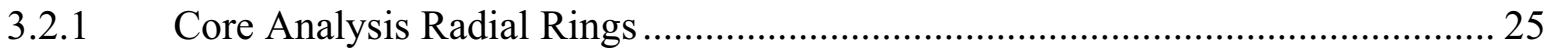

3.2.2 Core Unit Cell Representation.................................................................... 26

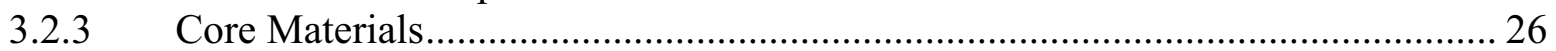

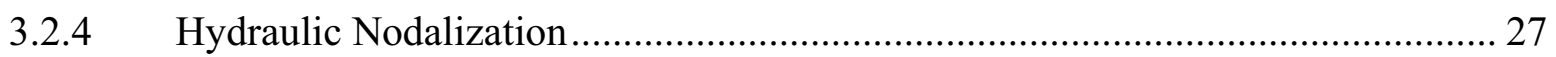

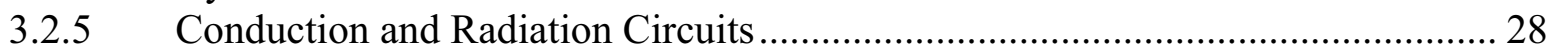

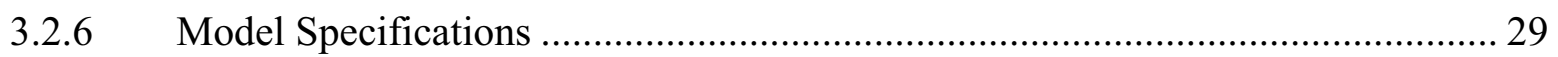

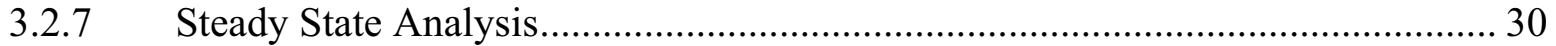

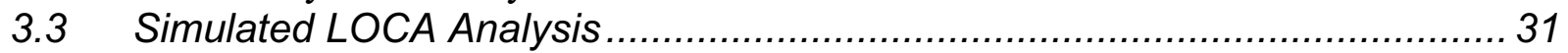

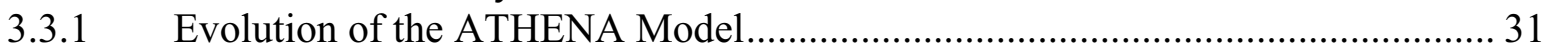

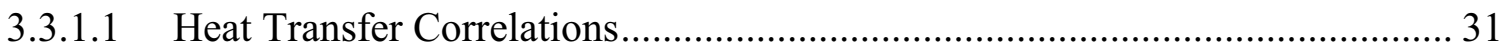

3.3.1.2 Influence of Guard Containment Back Pressure............................................... 34

3.3.1.3 Water Decay Heat Removal Loop ................................................................ 34

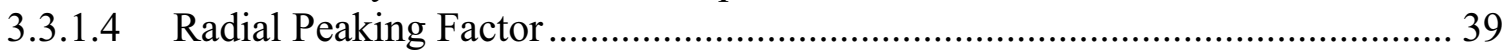

3.3.1.5 SiC Thermal Conductivity Investigation .......................................................... 41

3.3.1.6 Containment - RCCS Interface Modeling ....................................................... 41

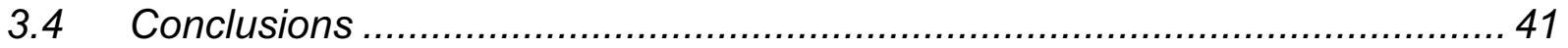




\section{Executive Summary}

The Idaho National Laboratory (INL) contribution to the Nuclear Energy Research Initiative (NERI) project number 2002-005 was divided into reactor physics, and thermal-hydraulics and plant design. The research targeted credible physics and thermal-hydraulics models for a gascooled fast reactor, analyzing various fuel and in-core fuel cycle options to achieve a true breed and burn core, and performing a design basis Loss of Coolant Accident (LOCA) analysis on that design.

For the physics analysis, a 1/8 core model was created using different enrichments and simulated equilibrium fuel loadings. The model was used to locate the hot spot of the reactor, and the peak to average energy deposition at that location. The model was also used to create contour plots of the flux and energy deposition over the volume of the reactor. The eigenvalue over time was evaluated using three different fuel configurations with the same core geometry. The breeding capabilities of this configuration were excellent for a 7\% U-235 model and good in both a plutonium model and a $14 \% \mathrm{U}-235$ model. Changing the fuel composition from the Pu fuel which provided about $78 \%$ U-238 for breeding to the $14 \%$ U-235 fuel with about $86 \%$ U-238 slowed the rate of decrease in the eigenvalue a noticeable amount. Switching to the $7 \%$ U-235 fuel with about $93 \%$ U-238 showed an increase in the eigenvalue over time.

For the thermal-hydraulic analysis, the reactor design used was the one forwarded by the MIT team. This reactor design uses helium coolant, a Brayton cycle, and has a thermal power of 600 MW. The core design parameters were supplied by MIT; however, the other key reactor components that were necessary for a plausible simulation of a LOCA were not defined. The thermal-hydraulic and plant design research concentrated on determining reasonable values for those undefined components.

The LOCA simulation was intended to provide insights on the influence of the Reactor Cavity Cooling System (RCCS), the containment building, and a Decay Heat Removal System (DHRS) on the natural circulation heat transfer of the core's decay heat. A baseline case for natural circulation had to be established in order to truly understand the impact of the added safety systems. This baseline case did not include a DHRS, although the current MIT design does have a DHRS that features the highly efficient Printed Circuit Heat Exchangers (PCHEs).

The initial LOCA analysis revealed that the RCCS was insufficient to maintain the reactor core below the fuel matrix decomposition temperature. A guard containment was added to the model in order to maintain a prescribed backpressure during the LOCA to enhance the natural circulation. The backpressure approach did provide satisfactory natural convection during the LOCA. The necessary backpressure was $1.8 \mathrm{MPa}$, which was not especially different from the values reported by other gas fast reactor researchers. However, as the model evolved to be more physically representative of a nuclear reactor, i.e., it included radial peaking factors, inlet plenum orificing, and the degradation of $\mathrm{SiC}$ thermal properties as a result of irradiation, the LOCAinduced fuel temperatures were not consistently below the decomposition limit. 


\section{Task A: Core Physics}

A $1 / 8$ core $\mathrm{MCNP}^{1}$ model of the breed and burn reactor has been created. The model contains 990 cells in which the fuel is smeared with the other core materials (coolant, matrix material, etc.) The radius of the core is $124 \mathrm{~cm}$ with the reflector extending another $100 \mathrm{~cm}$. The height of the core is $100 \mathrm{~cm}$ with a $100 \mathrm{~cm}$ thick reflector above and below the core.

The model was used to locate the hot spot of the reactor and the peak to average energy deposition at this location. This model was also used to create contour plots of the flux and energy deposition over the volume of the reactor. The eigenvalue over time was evaluated using three different fuel configurations with the same core geometry.

The model was also used to look at the breed and burn aspects of a variety of isotopes in different fuel configurations. The details of these analyses and the results are discussed here. Results have been presented previously for this reactor using a very low (unrealistic) power level for the depletion steps. This error has been corrected with the corrected data presented here.

\subsection{Model Details}

The model was created using the lattice fill method of MCNP. Each of the fuel cells is a right hexagonal prism $10 \mathrm{~cm}$ across the flats and $10 \mathrm{~cm}$ high. Each fuel cell is a unique universe with a unique material number. This provides the ability to deplete each fuel cell using the MOCUP ${ }^{2}$ code (MCNP-ORIGEN2 Coupled Utility Program). The azimuthal boundaries are modeled as reflective surfaces to take advantage of symmetry and mimic a full core without extending the

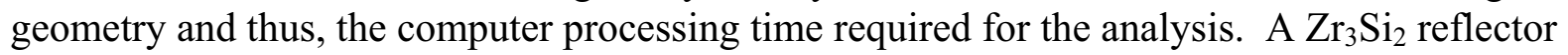
extends $100 \mathrm{~cm}$ beyond the active core radially and $100 \mathrm{~cm}$ above and below the core axially. The source was defined as a uniformly distributed source over the volume of the active core. Figures 1 and 2 present a radial cross section of the core at the mid plane and an axial cross section through the hotspot. Both figures include the cell numbers for referencing purposes later.

MOCUP uses tally information from MCNP to provide material composition, flux, and collapsed 1-group cross sections for ORIGEN $2^{3}$ depletion calculations. MOCUP calculates the necessary information and inserts it into the ORIGEN2 input file before initiating the ORIGEN2 run. The ORIGEN2 output is then used by MOCUP to calculate the new material composition for the depleted cell, generate a new material card, and then insert it into the next MCNP input file. MOCUP then runs MCNP with the new input file to calculate the new eigenvalue and new flux and cross sections. This process is performed for each depletion cell for each depletion step. The depletion cycles were set up to occur at 60 day increments for 24 cycles which is equal to about 3.9 years. 


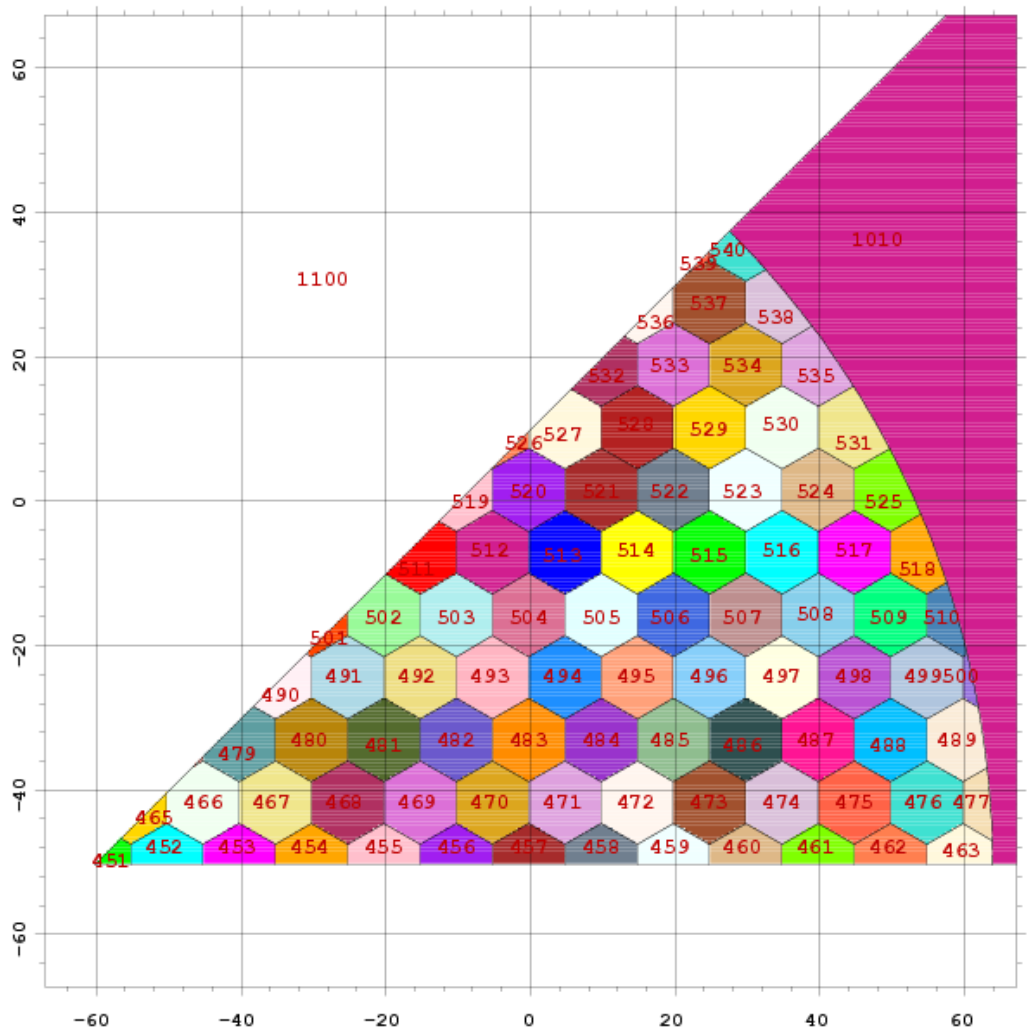

Figure 1: Radial cross section through the mid plane of the core showing the MCNP cell number

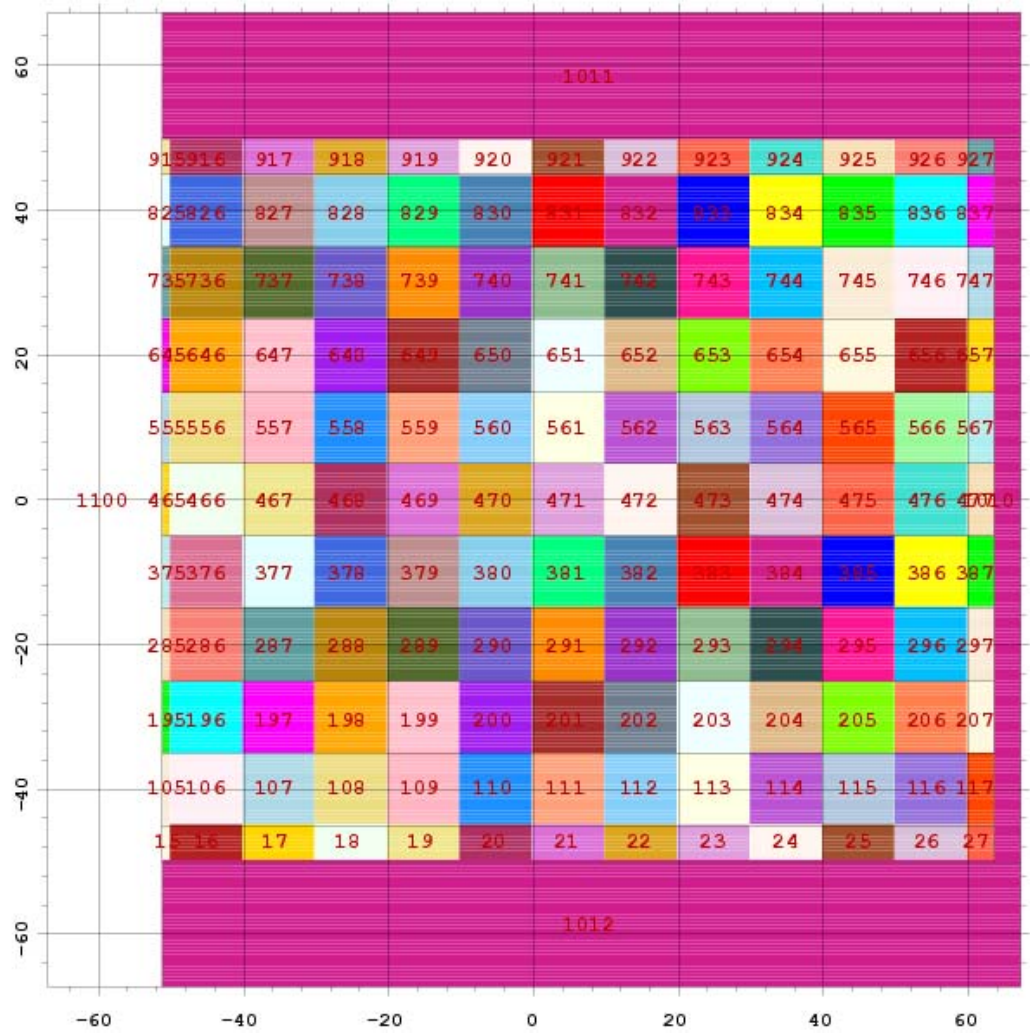

Figure 2: Axial cross section of the core through the hot spot showing the MCNP cell numbers. 
This same geometric model was run with three different fuel compositions. The first was a uranium carbide fuel with 16 weight percent plutonium, 4 weight percent in major actinides (neptunium, americium, and curium), and the rest being natural uranium. The second and third fuel compositions contained no plutonium or major actinides, but were enriched to $14 \%$ U-235 and $7 \% \mathrm{U}-235$ respectively. The plutonium-fueled model at BOL was used to determine the location of the hot spot and to calculate the peak to average ratio for this location. It was also used to evaluate the neutron spectrum, and generate contour plots of the energy and neutron flux. A cylindrical mesh tally was set up for MCNPX to provide the data for the contour plot. The MCNPX plotting feature was used to generate the contour plots.

\subsection{Neutronics Results}

From the BOL Pu fueled model, a variety of important neutronics information was generated for this core configuration. A tally in each cell determined that the hot spot of the core occurs in cell 467 with the peak to average at that location being 2.3. Figure 3 shows a neutron flux spectrum for the hot spot of the core and average over the active core. As is expected, the spectrum is consistent with a fast reactor spectrum.

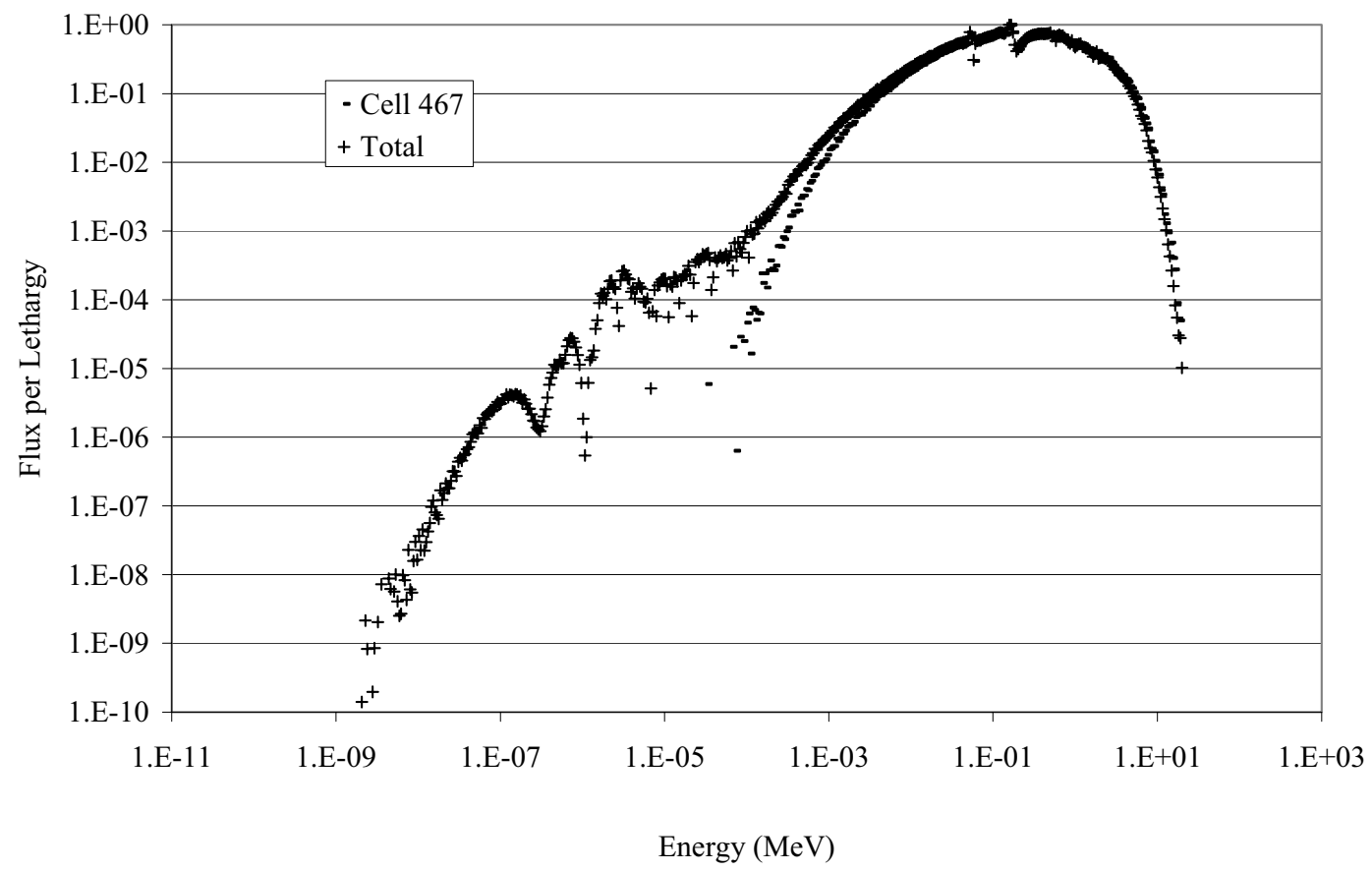

Figure 3: Plot of the flux per lethargy for cell 467 which is the location of the hot spot of the core, and the average spectrum over the whole active core.

Figures 4 through 7 show contour plots for the radial flux profile, the axial flux profile, the radial total energy deposition profile, and the axial total energy profile respectively. 
08/11/05 12:39:20

GFR Carbide Fuel He cooled

probid $=08 / 10 / 05 \quad 15: 49: 30$

basis: $x y$

$(1.000000,0.000000,0.000000)$

$(0.000000,1.000000,0.000000)$

origin:

( $116.93,89.06,50.00$ )

extent $=($ 119.61, 119.61)

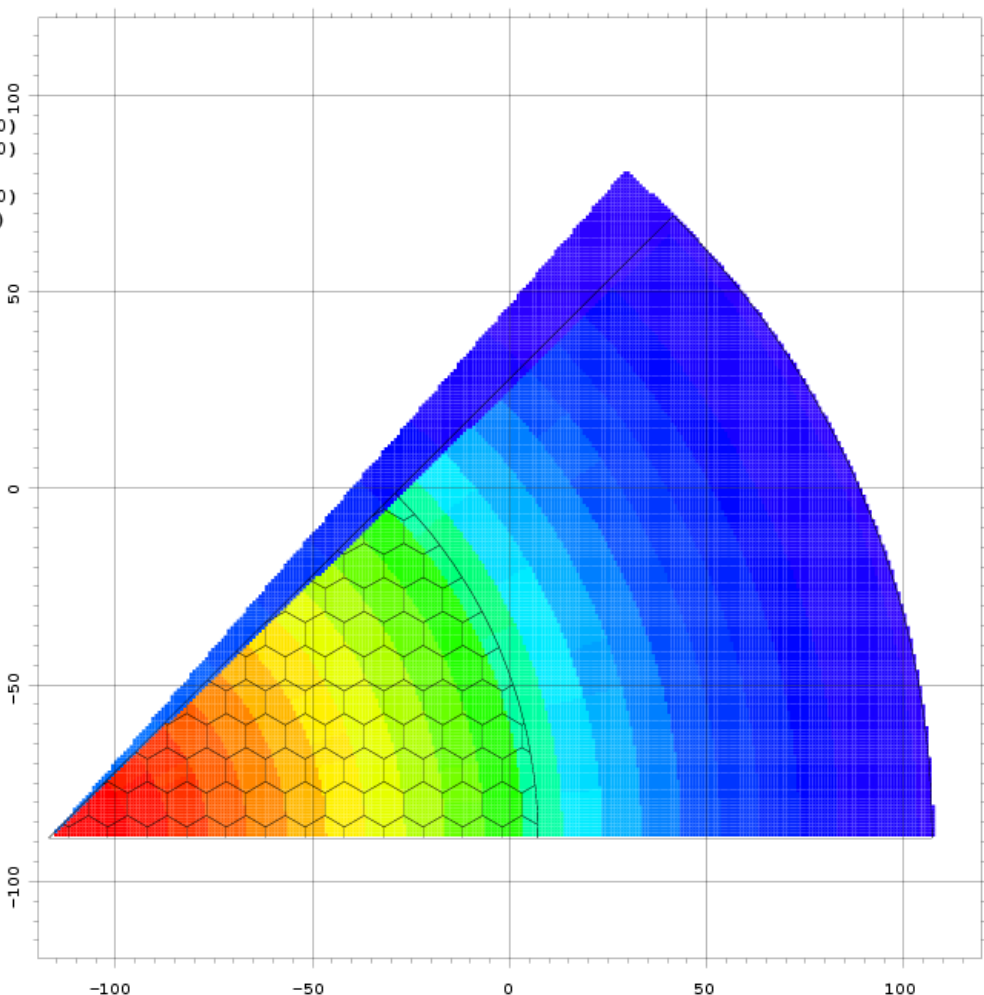

Figure 4: Radial Flux profile at the mid-plane of the core.

08/11/05 12:43:08

GFR Carbide Fuel He cooled

probid $=08 / 10 / 05 \quad 15: 49: 30$

basis: $\mathrm{xz}$

$(1.000000,0.000000,0.000000)$

$(0.000000,0.000000,1.000000)$

(112.74, 1.00, 50.00 \$

extent $=(\quad 156.82, \quad 156.82)$

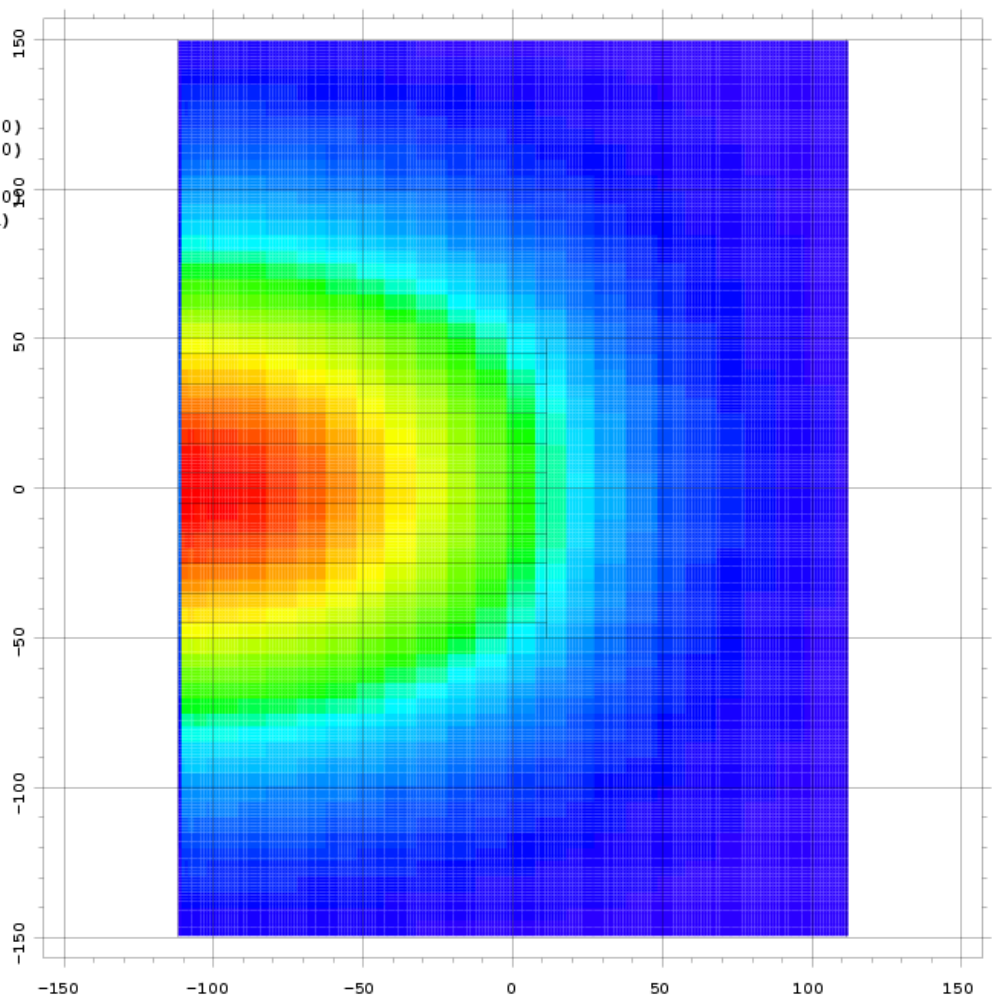

Figure 5: Axial flux profile through the center of the core. 


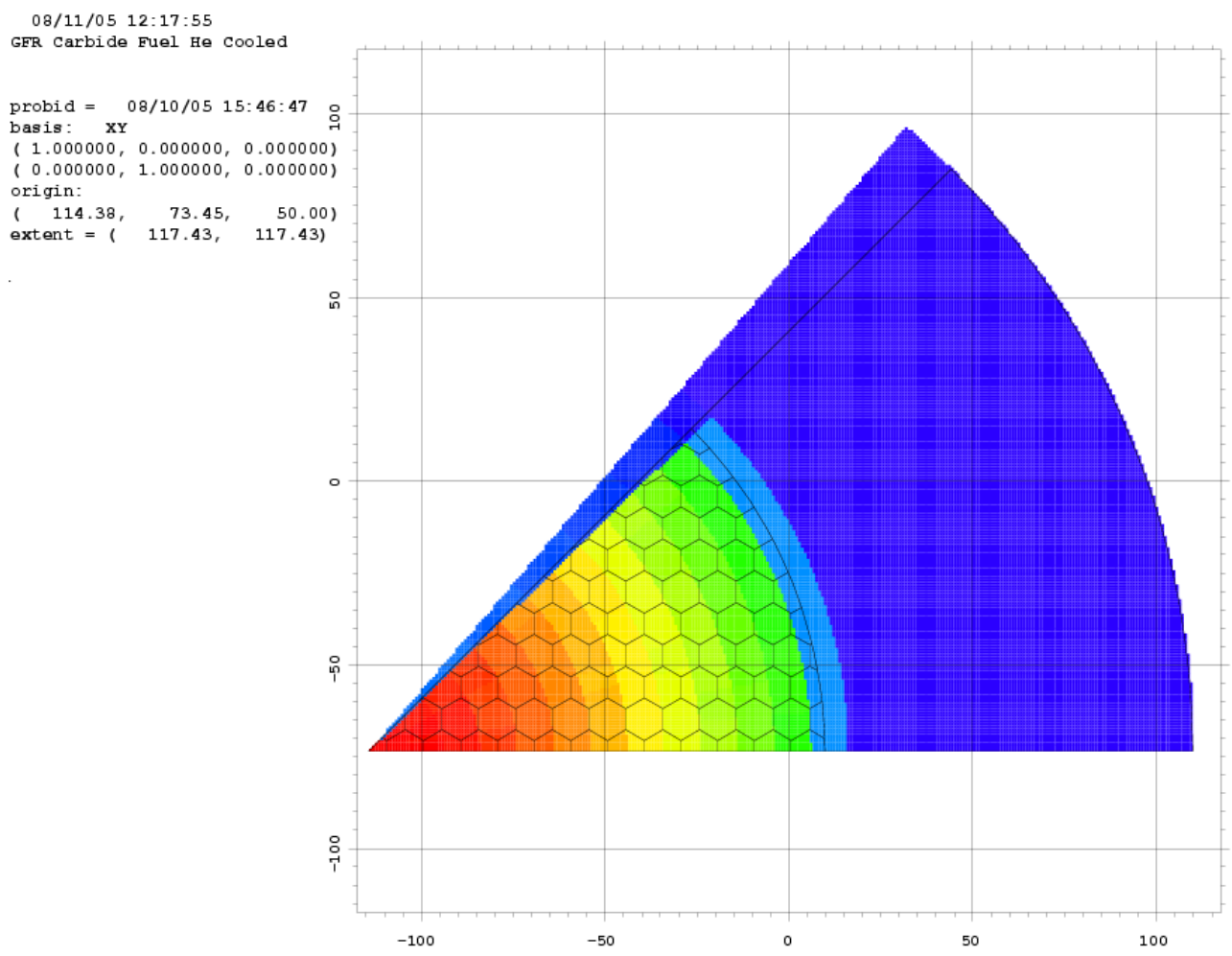

Figure 6: Radial heating profile at the mid-plane of the core.

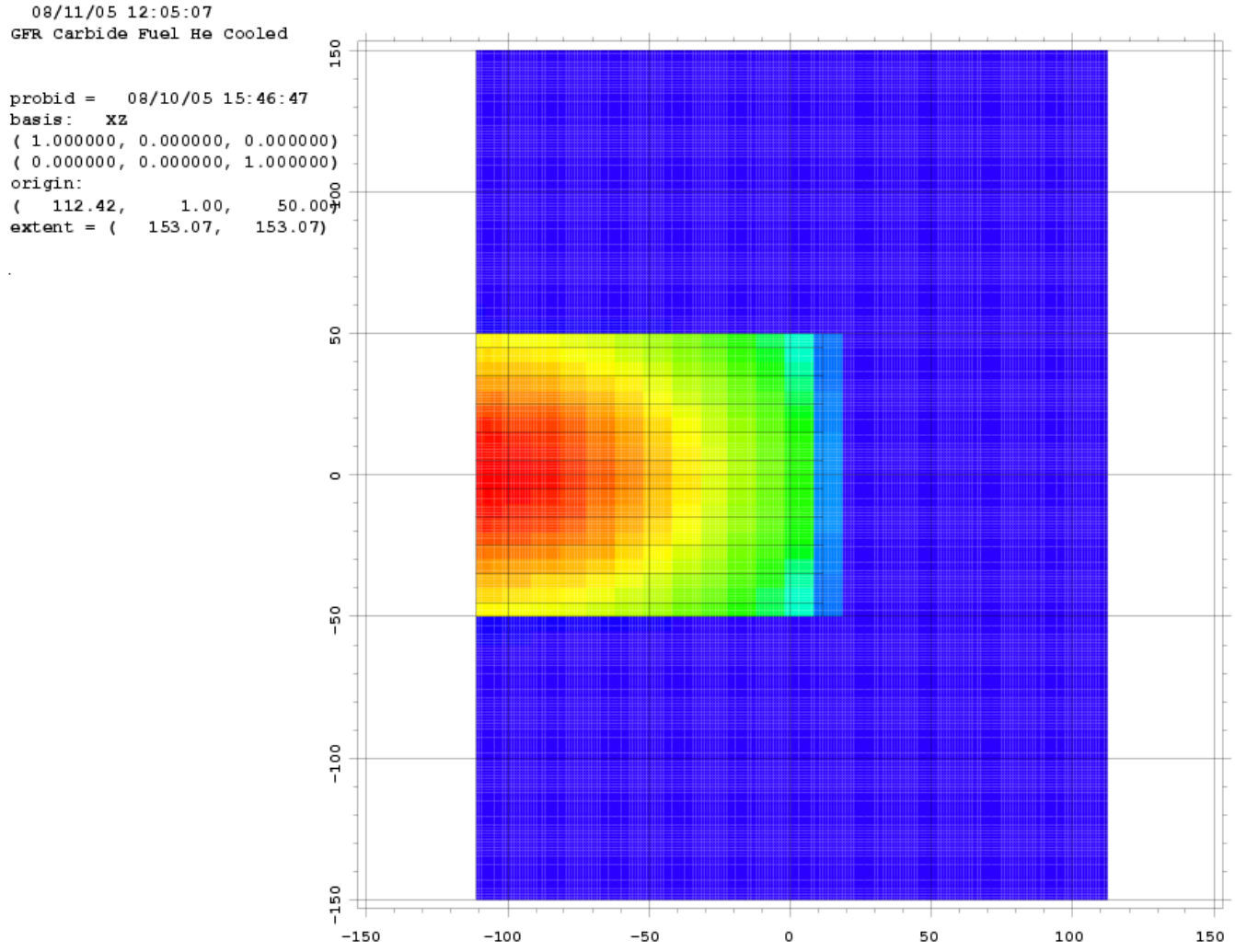

Figure 7: Axial heating profile through he center of the core. 
The combination of the limited color resolution for the MCNPX contour plots combined with the difference in the energy deposition rate in the active core as compared to the reflector (about two orders of magnitude) results in the reflector in the contour plot being represented as one color.

The neutronics data presented in the previous figures is what you would expect from this configuration, and is an indication that this model is representative of the configuration.

\subsection{Plutonium Fueled Depletion Model}

As mentioned previously, MOCUP was used to couple MCNP and ORIGEN2 to estimate the effects of fuel burn-up over several years worth of run time. The reactor specifications for the $\mathrm{Pu}$ fueled depletion model are presented in Table 1. The dimensions presented in the table are for the complete core geometry and not the $1 / 8$ core model. The volume and power of the $1 / 8$ model is $0.604 \mathrm{~m}^{3}$ and $60.4 \mathrm{MW}$ respectively.

The effect of fuel burn-up on the eigenvalue of the reactor is presented in Figure 8. The decrease in the eigenvalue is approximately $0.027 \Delta \mathrm{k}(1.183$ to 1.156$)$ in four years. Four years corresponds to about $38 \mathrm{MWd} / \mathrm{kg}$ of heavy metal. The change in the individual fuel isotopes is best viewed in graphical form. The isotopes of uranium, neptunium, plutonium, americium, and curium are displayed in Figures 9 through 13.

The uranium isotopes and the Np-237 isotope show a significant depletion over the time period evaluated. $\mathrm{Pu}-239$ and $\mathrm{Pu}-241$ deplete gradually over the time period while $\mathrm{Pu}-238$ and $\mathrm{Pu}-242$ show an increase. The concentration of Pu-240 stays relatively constant. Am-241, Am-242, and Am-243 deplete gradually over the time period. Am-242m increases over time and approaches a steady state concentration. Cm-244 gradually increases over time while Cm-242 and Cm-243 approach a steady state concentration. 
Table 1: Plutonium fueled Gas-Cooled Fast Reactor specifications.

\begin{tabular}{|l|l|}
\hline \multicolumn{2}{|c|}{ Overall Core Specifications } \\
\hline Power Density & $100 \mathrm{~W} / \mathrm{cm}^{3}$ \\
\hline Height & $1 \mathrm{~m}$ \\
\hline Radius & $1.24 \mathrm{~m}$ \\
\hline Volume Coolant Specifications \\
\hline Total Power & $4.83 \mathrm{~m}^{3}$ \\
\hline \multicolumn{2}{|c|}{483} \\
\hline Coolant Fuel Block Specifications \\
\hline System Pressure & $\mathrm{He}$ \\
\hline Coolant Volume Fraction & $7 \mathrm{MPa}$ \\
\hline \multicolumn{2}{|c|}{ Renal prism } \\
\hline Shape & $10 \mathrm{~cm}$ \\
\hline Height & $10 \mathrm{~cm}$ \\
\hline Dimension across flats & 990 \\
\hline Quantity & $60 \%$ \\
\hline Fuel + Matrix Volume Fraction & $\mathrm{UC}$ \\
\hline Fuel & $\mathrm{SiC}$ \\
\hline Matrix Material & $50 \%$ \\
\hline Fuel to Matrix Ratio & $78.94 \%$ \\
\hline \multicolumn{2}{|c|}{ Fuel Constituents } \\
\hline Natural Uranium & $16.85 \%$ \\
\hline Pu & $0.33 \%$ \\
\hline Pu-238 & $9.75 \%$ \\
\hline Pu-239 & $4.39 \%$ \\
\hline Pu-240 & $1.69 \%$ \\
\hline Pu-241 & $0.68 \%$ \\
\hline Pu-242 & $4.21 \%$ \\
\hline Minor Actinides & $1.81 \%$ \\
\hline Np-237 & $1.89 \%$ \\
\hline Am-241 & $0.38 \%$ \\
\hline Am-243 & $0.13 \%$ \\
\hline Cm-244 & $\mathrm{Zr} \mathrm{Si}_{2}$ \\
\hline \multicolumn{2}{|c|}{$1 \mathrm{~m}$} \\
\hline Reflector Material & $\mathrm{m}$ \\
\hline Axial Thickness & \\
\hline Radial Thickness & \\
\hline \multicolumn{2}{|c|}{ Cocifications } \\
\hline
\end{tabular}




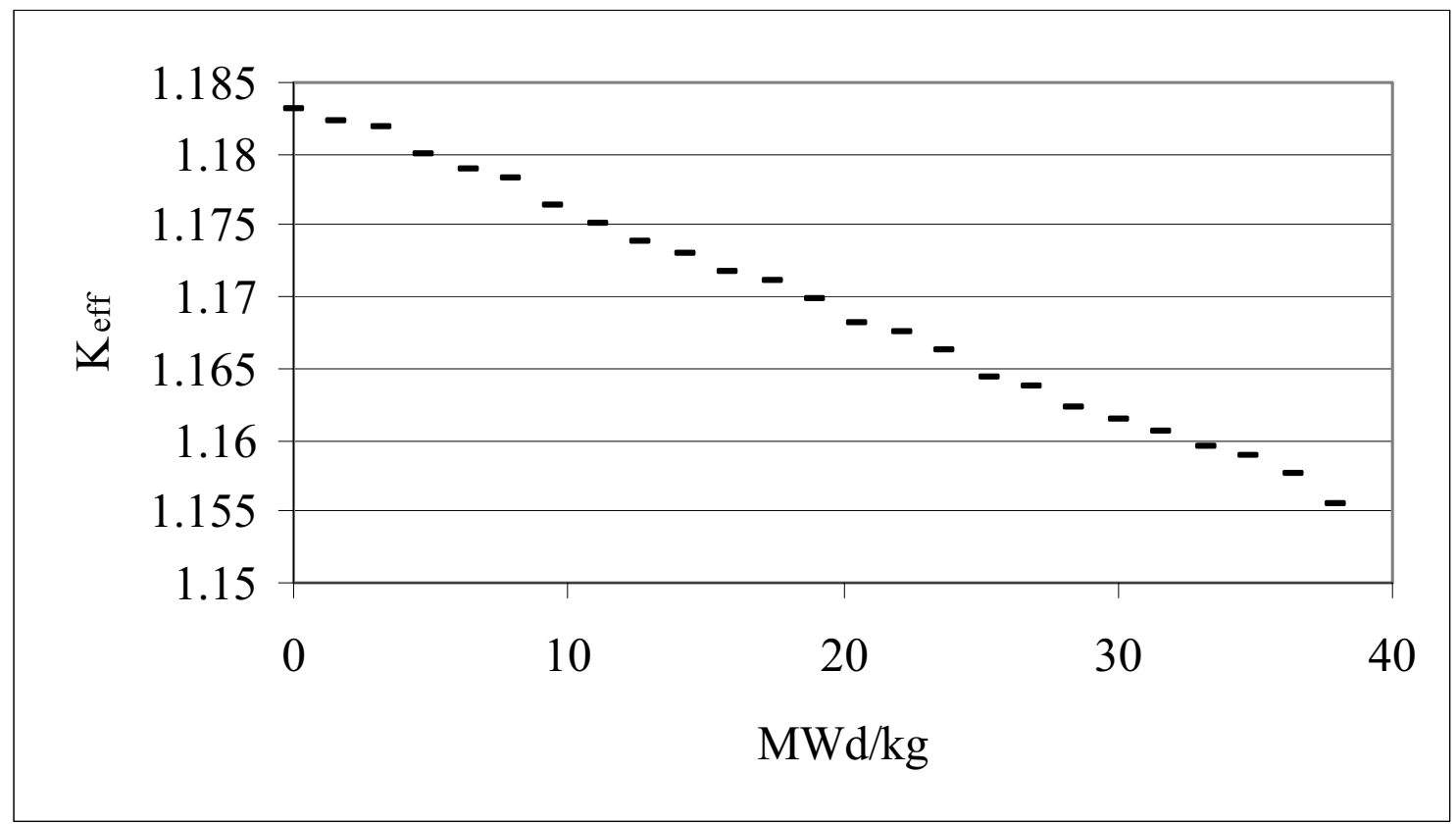

Figure 8: Change in $\mathrm{K}_{\text {eff }}$ vs. burn-up in the plutonium fueled model.

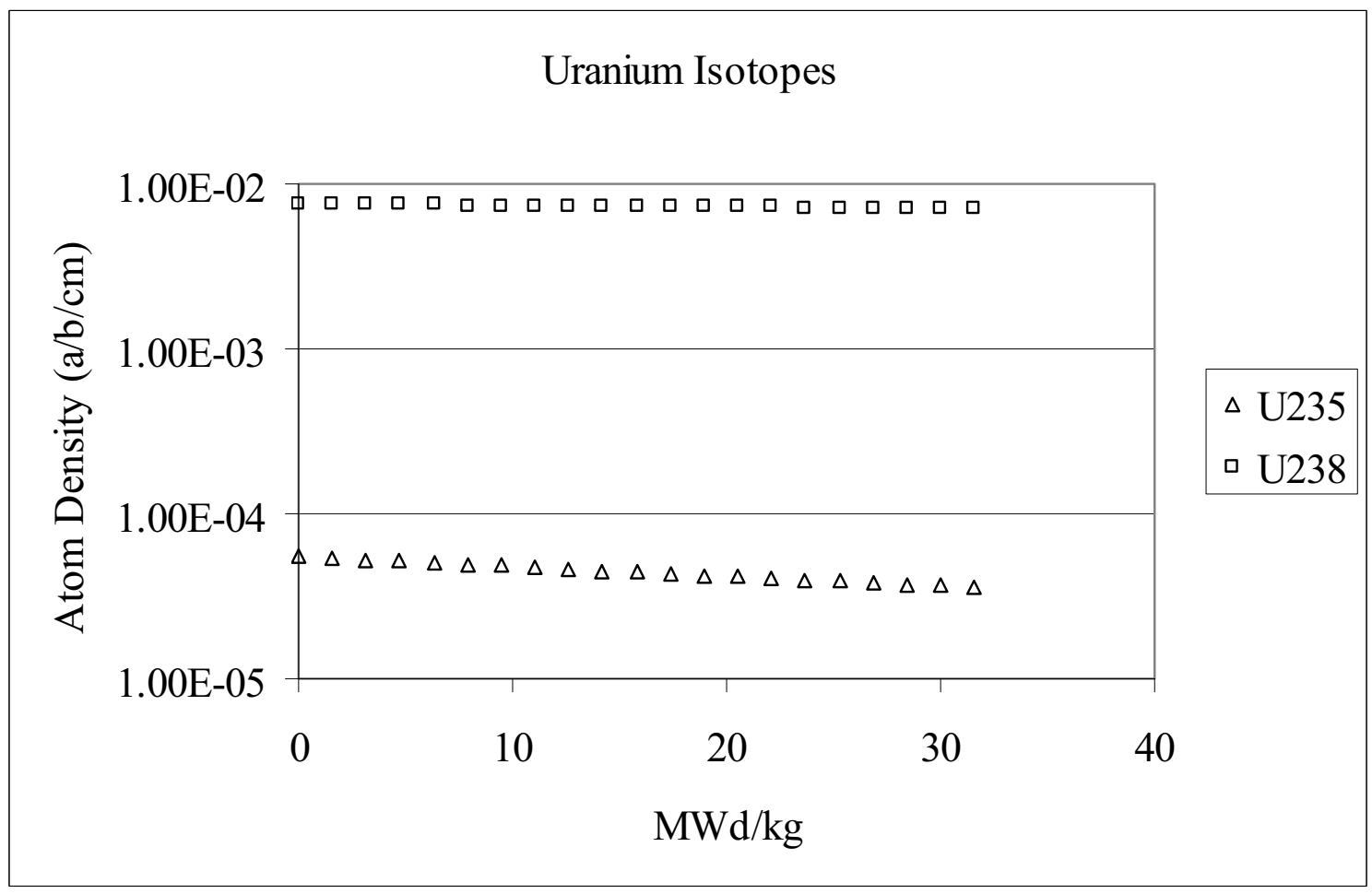

Figure 9: Change in the uranium composition of the fuel vs. burn-up in the plutonium fueled model. 


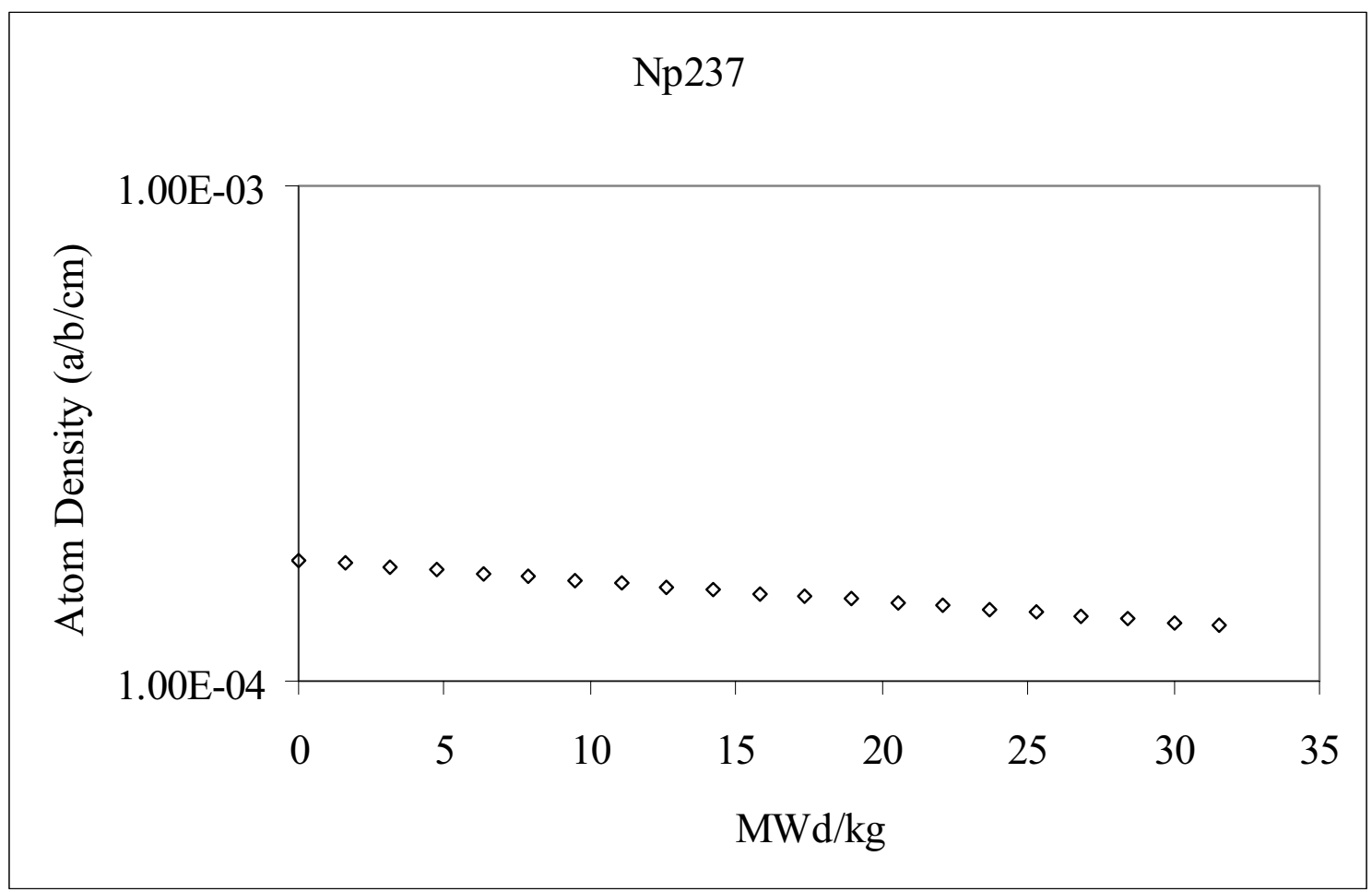

Figure 10: Change in the neptunium composition of the fuel vs. burn-up in the plutonium fueled model.

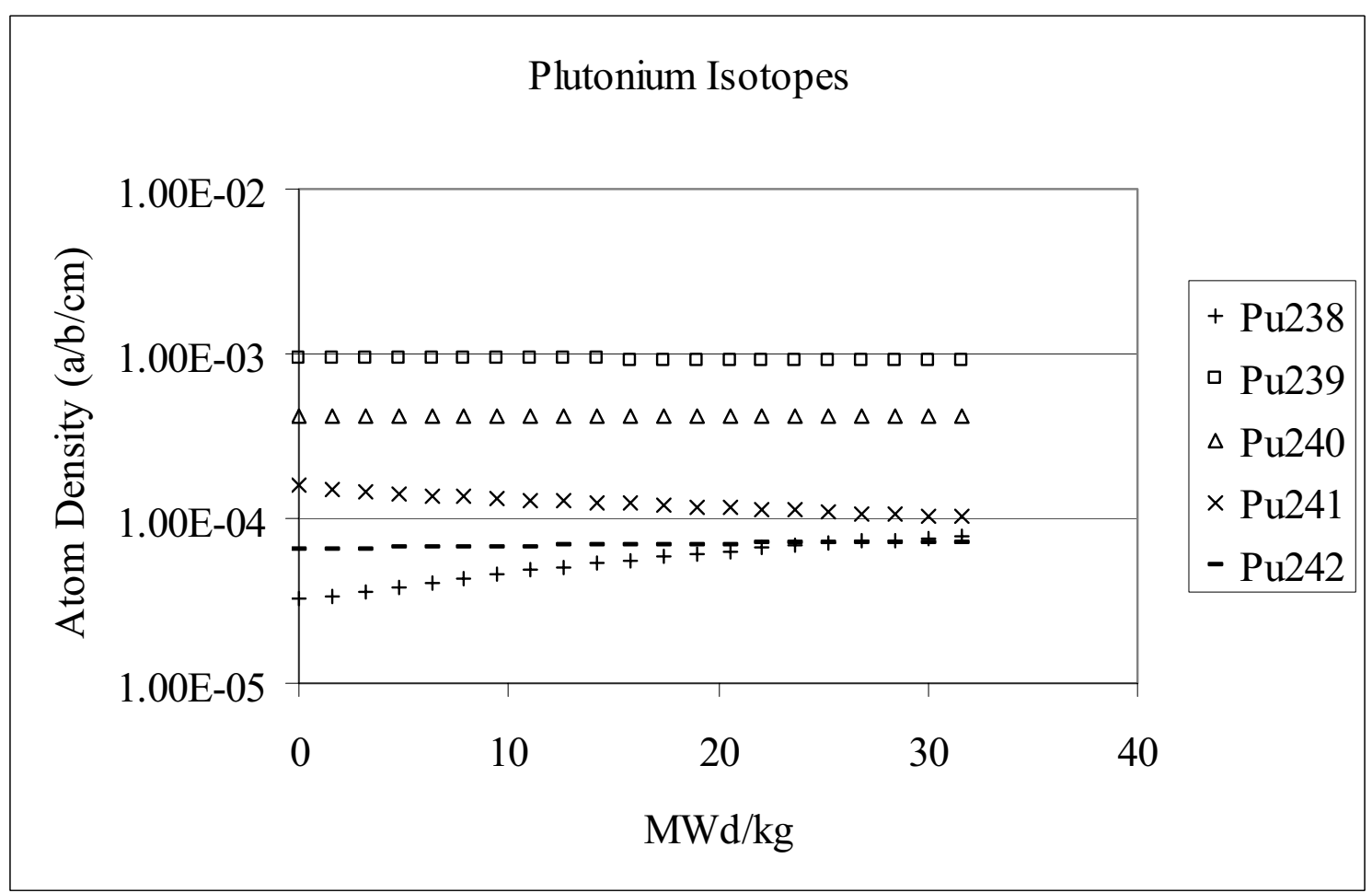

Figure 11: Change in the plutonium composition of the fuel vs. burn-up in the plutonium fueled model. 


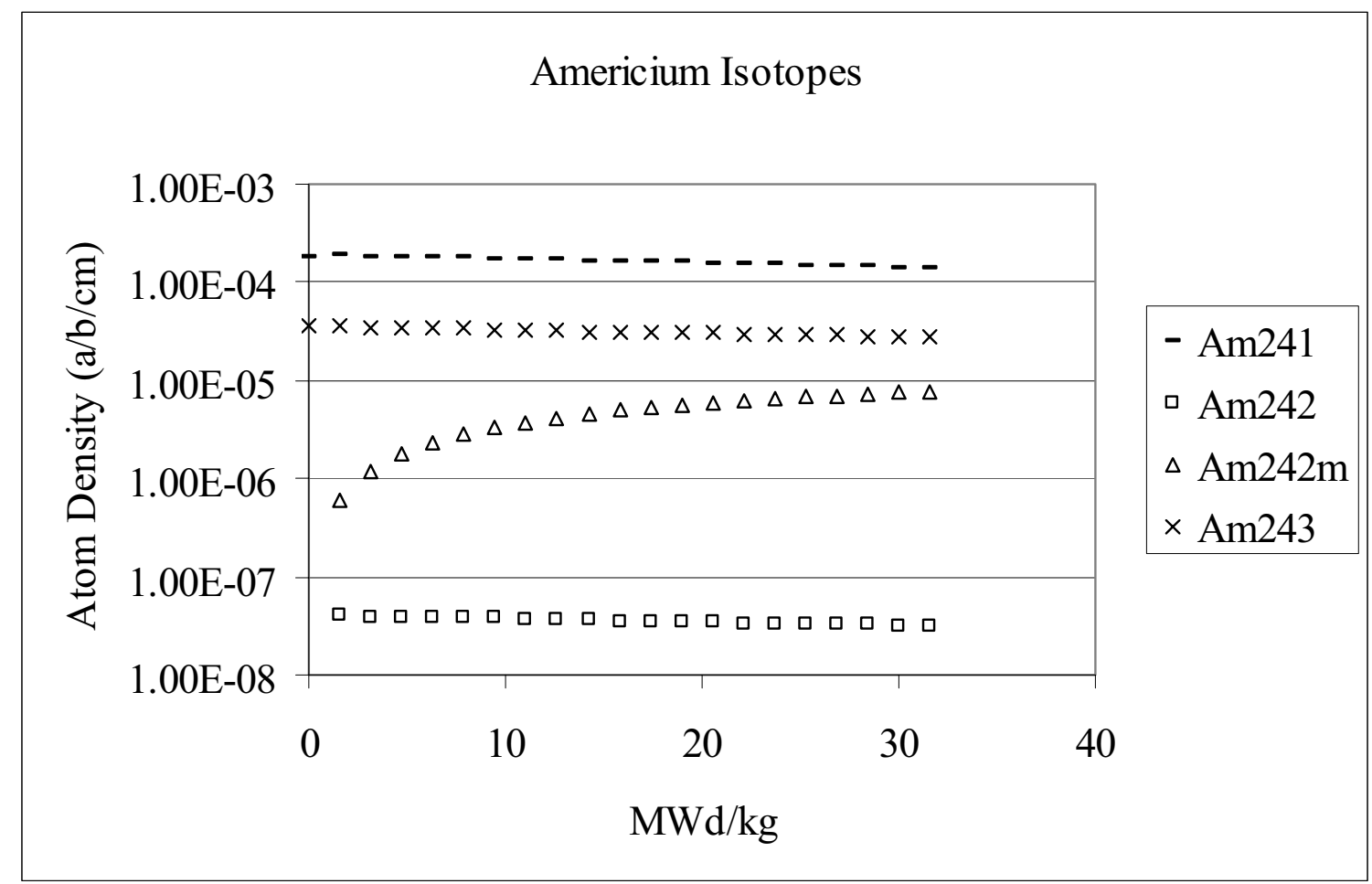

Figure 12: Change in the americium composition of the fuel vs. burn-up in the plutonium fueled model.

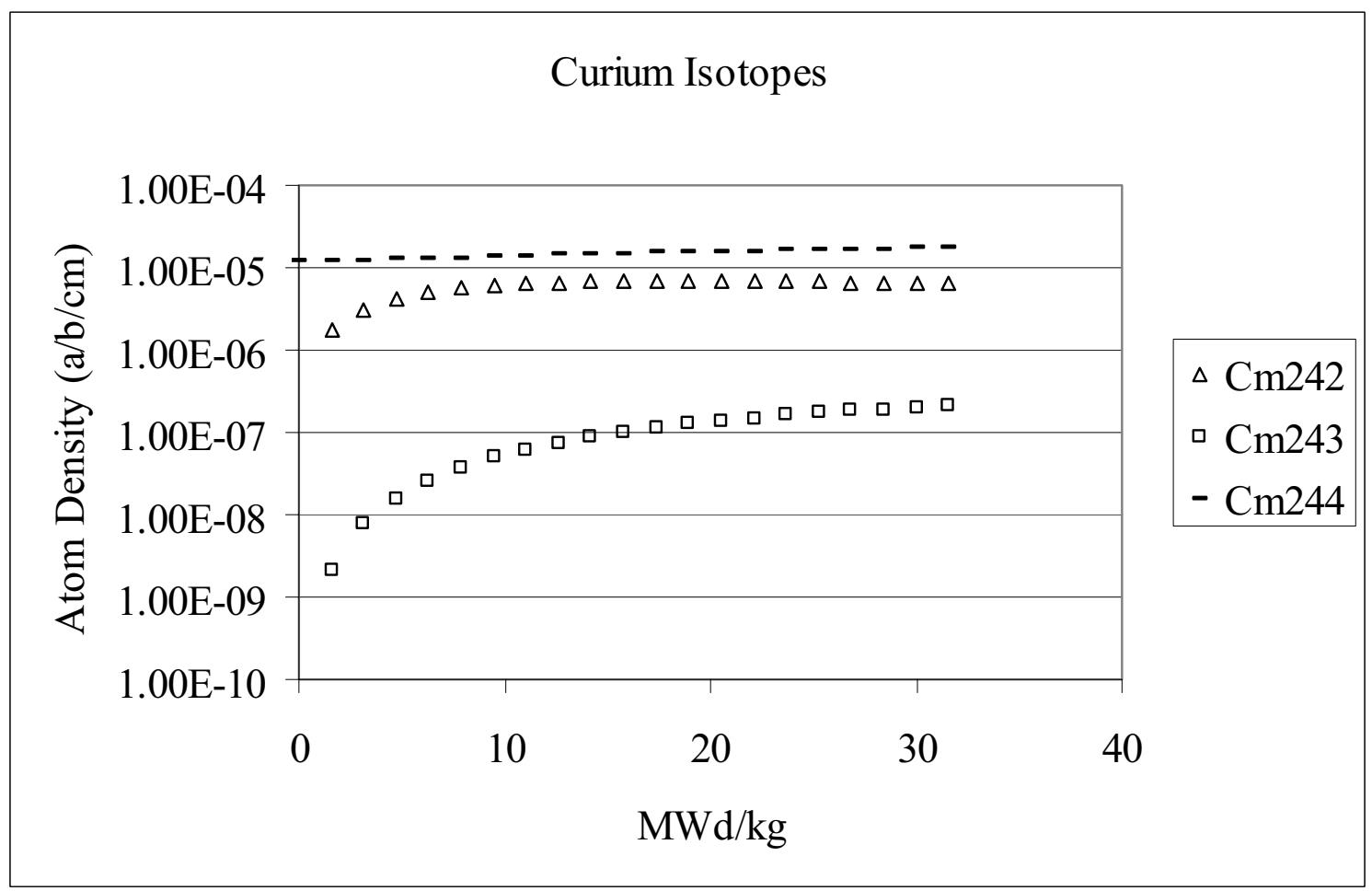

Figure 13: Change in the curium composition of the fuel vs. burn-up in the plutonium fueled model. 


\subsection{4\% Enriched Uranium Fueled Depletion Model}

The reactor specifications for the 14\% U-235 fueled depletion model are presented in Table 2. The effect of fuel burn-up on the eigenvalue of the reactor is presented in Figure 14. The decrease in the eigenvalue is approximately $0.016 \Delta \mathrm{k}(1.054$ to 1.038$)$ in four years. The isotopes of uranium, neptunium, plutonium, americium, and curium are displayed in Figures 15 through 19.

The uranium isotopes deplete over time with U-235 showing a significant depletion. All of the other isotopes (Np-237, Pu-238, Pu-239, Pu-240, Pu-241, Pu-242, Am-241, Am-242, Am-242m, Am-243, Cm-242, Cm-243, and Cm244) increase over time and approach a steady state concentration.

Table 2: 14\% U-235 fueled Gas-Cooled Fast Reactor specifications.

Overall Core Specifications

\begin{tabular}{|c|c|}
\hline Power Density & $100 \mathrm{~W} / \mathrm{cm}^{3}$ \\
\hline Height & $1 \mathrm{~m}$ \\
\hline Radius & $1.24 \mathrm{~m}$ \\
\hline Volume & $4.83 \mathrm{~m}^{3}$ \\
\hline Total Power & $483 \mathrm{MW}$ \\
\hline \multicolumn{2}{|c|}{ Coolant Specifications } \\
\hline Coolant & $\mathrm{He}$ \\
\hline System Pressure & $7 \mathrm{MPa}$ \\
\hline Coolant Volume Fraction & $40 \%$ \\
\hline \multicolumn{2}{|c|}{ Fuel Block Specifications } \\
\hline Shape & Hexagonal prism \\
\hline Height & $10 \mathrm{~cm}$ \\
\hline Dimension across flats & $10 \mathrm{~cm}$ \\
\hline Quantity & 990 \\
\hline Fuel + Matrix Volume Fraction & $60 \%$ \\
\hline Fuel & UC \\
\hline Matrix Material & $\mathrm{SiC}$ \\
\hline Fuel to Matrix Ratio & $50 \%$ \\
\hline \multicolumn{2}{|c|}{ Fuel Constituents } \\
\hline $\mathrm{U}-234$ & $0.01 \%$ \\
\hline U-235 & $13.85 \%$ \\
\hline $\mathrm{U}-238$ & $86.15 \%$ \\
\hline \multicolumn{2}{|c|}{ Reflector Specifications } \\
\hline Reflector Material & $\mathrm{Zr}_{3} \mathrm{Si}_{2}$ \\
\hline Axial Thickness & $1 \mathrm{~m}$ \\
\hline Radial Thickness & $1 \mathrm{~m}$ \\
\hline
\end{tabular}




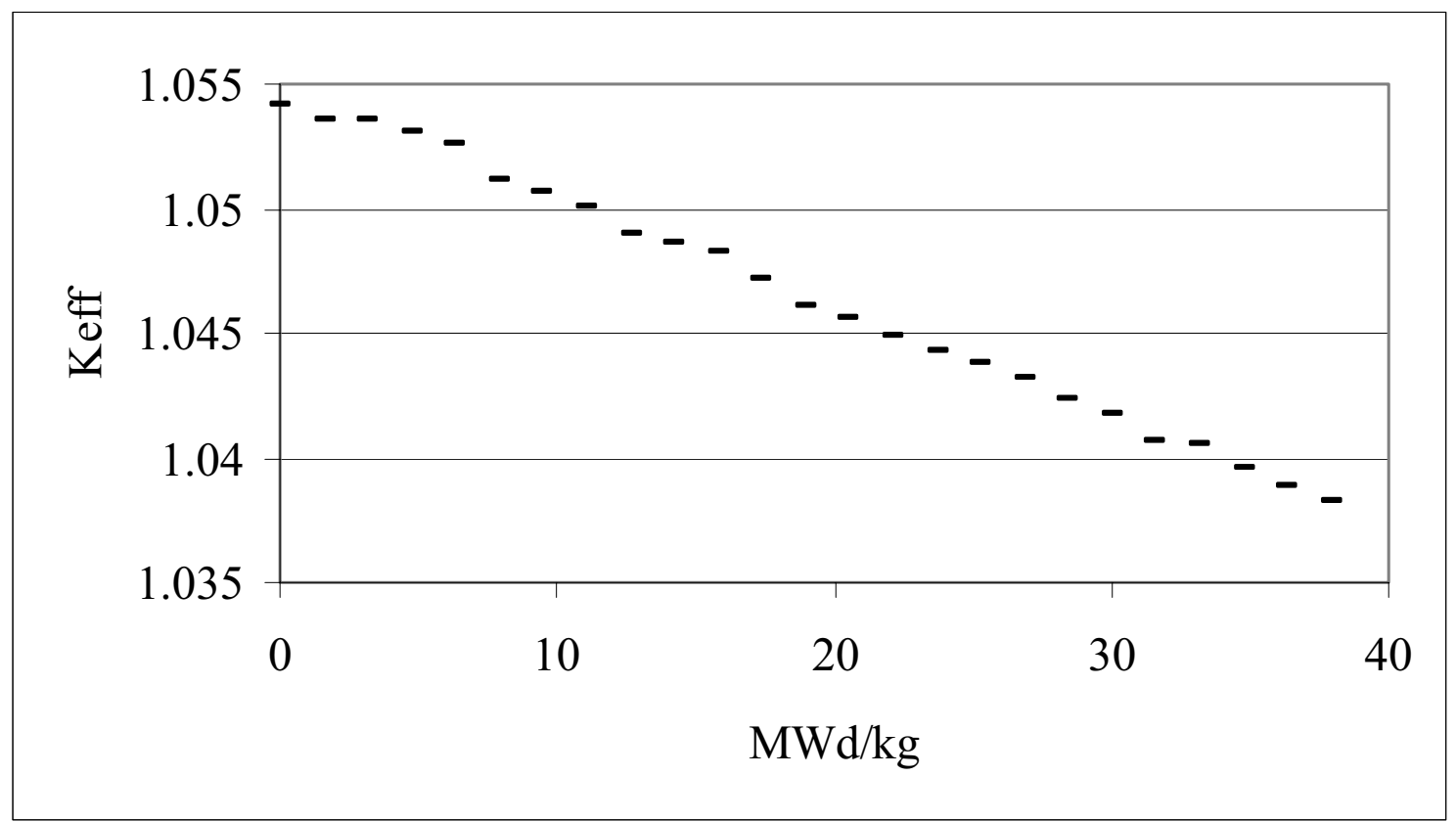

Figure 14: Change in $\mathrm{K}_{\text {eff }}$ vs. burn-up in the 14\% U-235 fueled model.

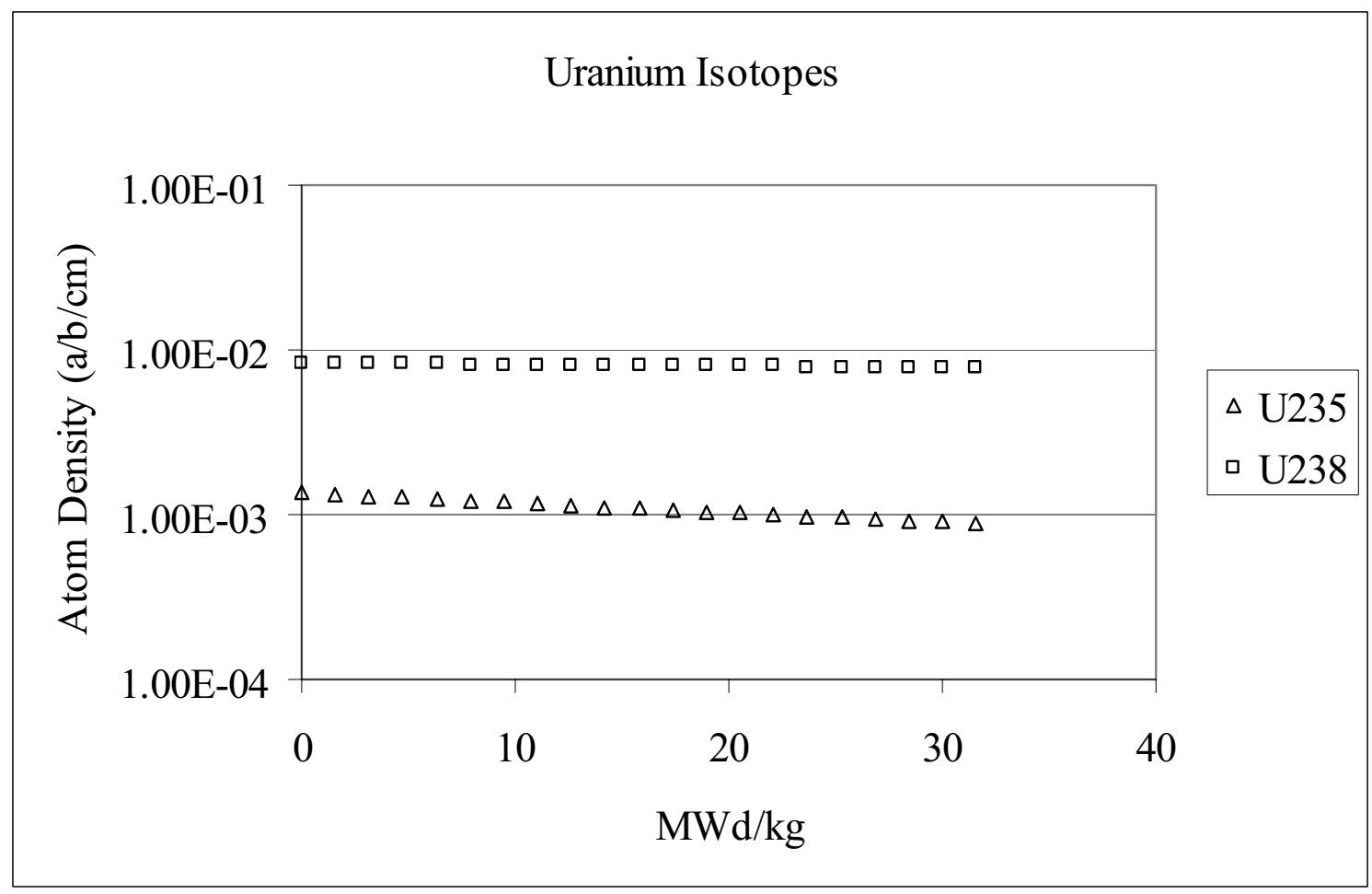

Figure 15: Change in the uranium composition of the fuel vs. burn-up in the 14\% U-235 fueled model. 


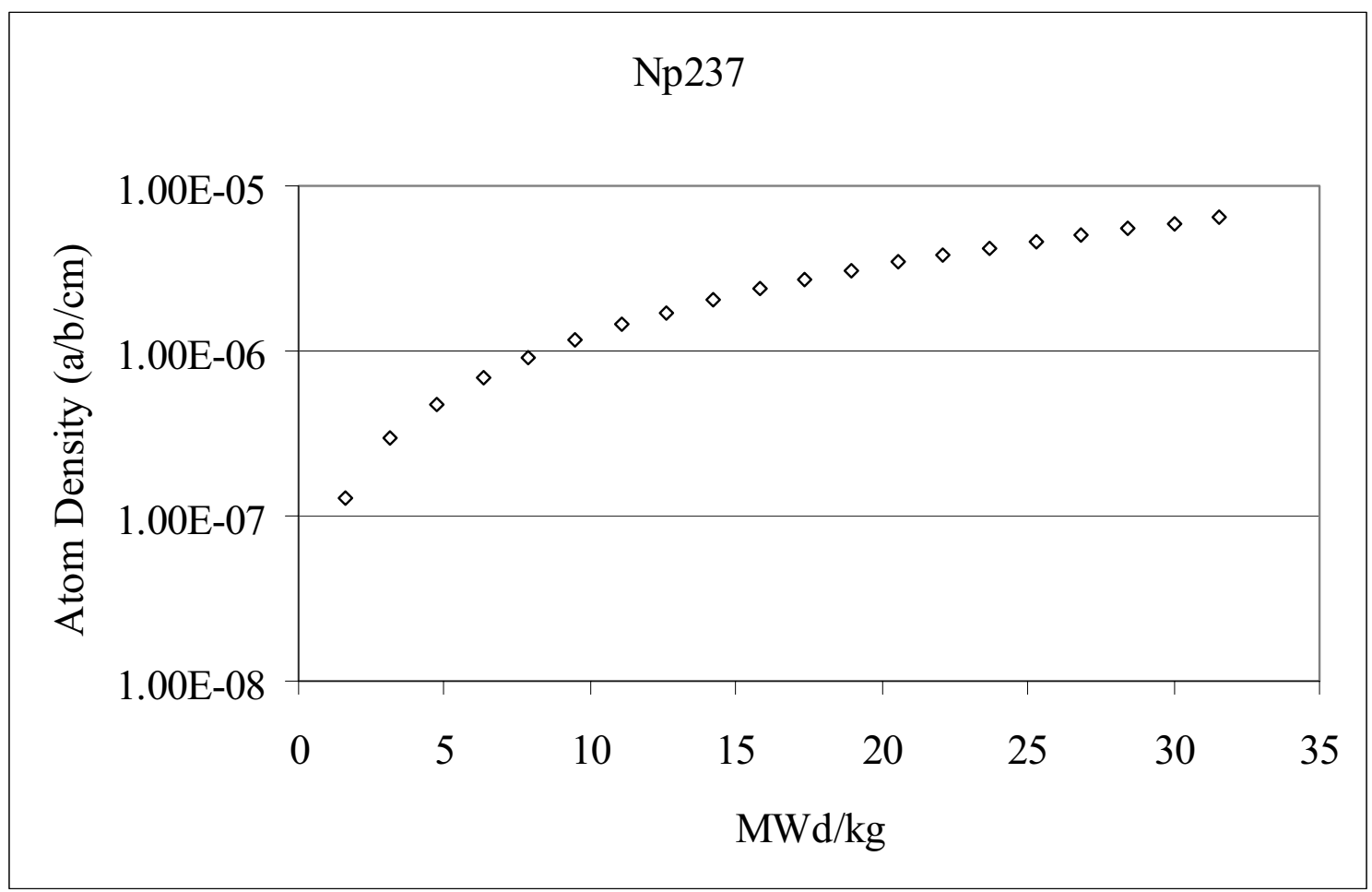

Figure 16: Change in the neptunium composition of the fuel vs. burn-up in the 14\% U-235 fueled model.

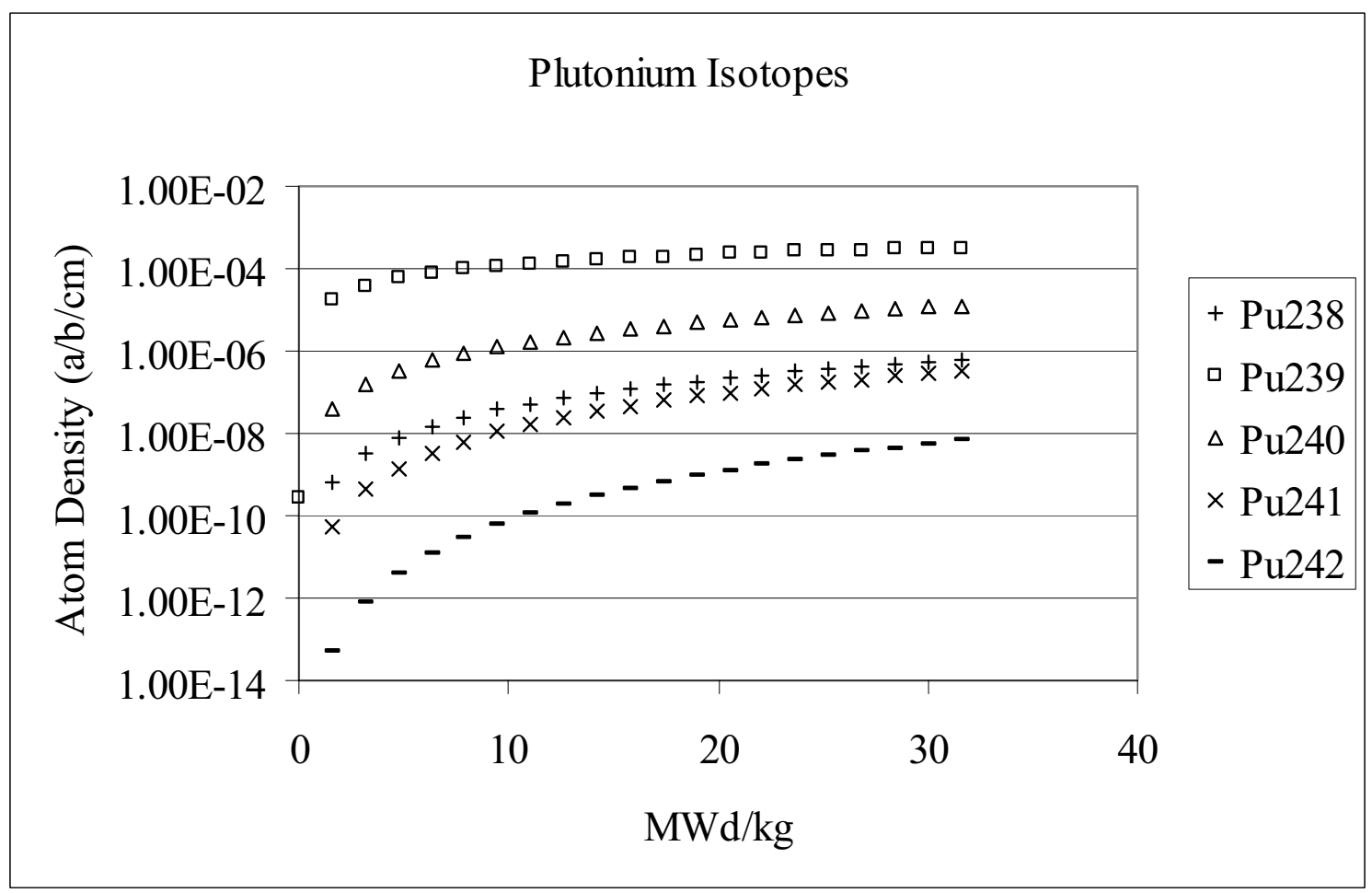

Figure 17: Change in the plutonium composition of the fuel vs. burn-up in the $14 \%$ U-235 fueled model. 


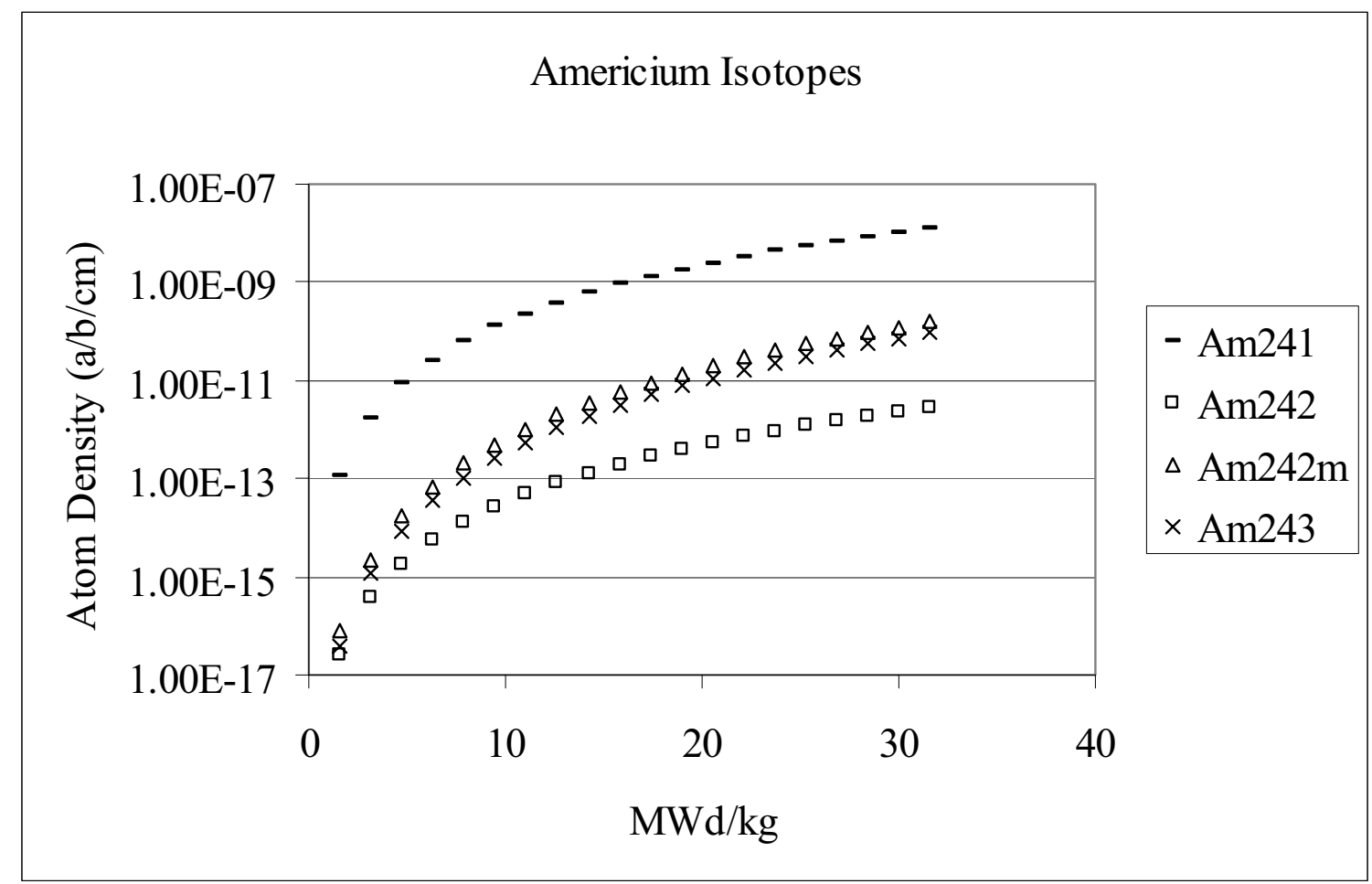

Figure 18: Change in the americium composition of the fuel vs. burn-up in the $14 \%$ U-235 fueled model.

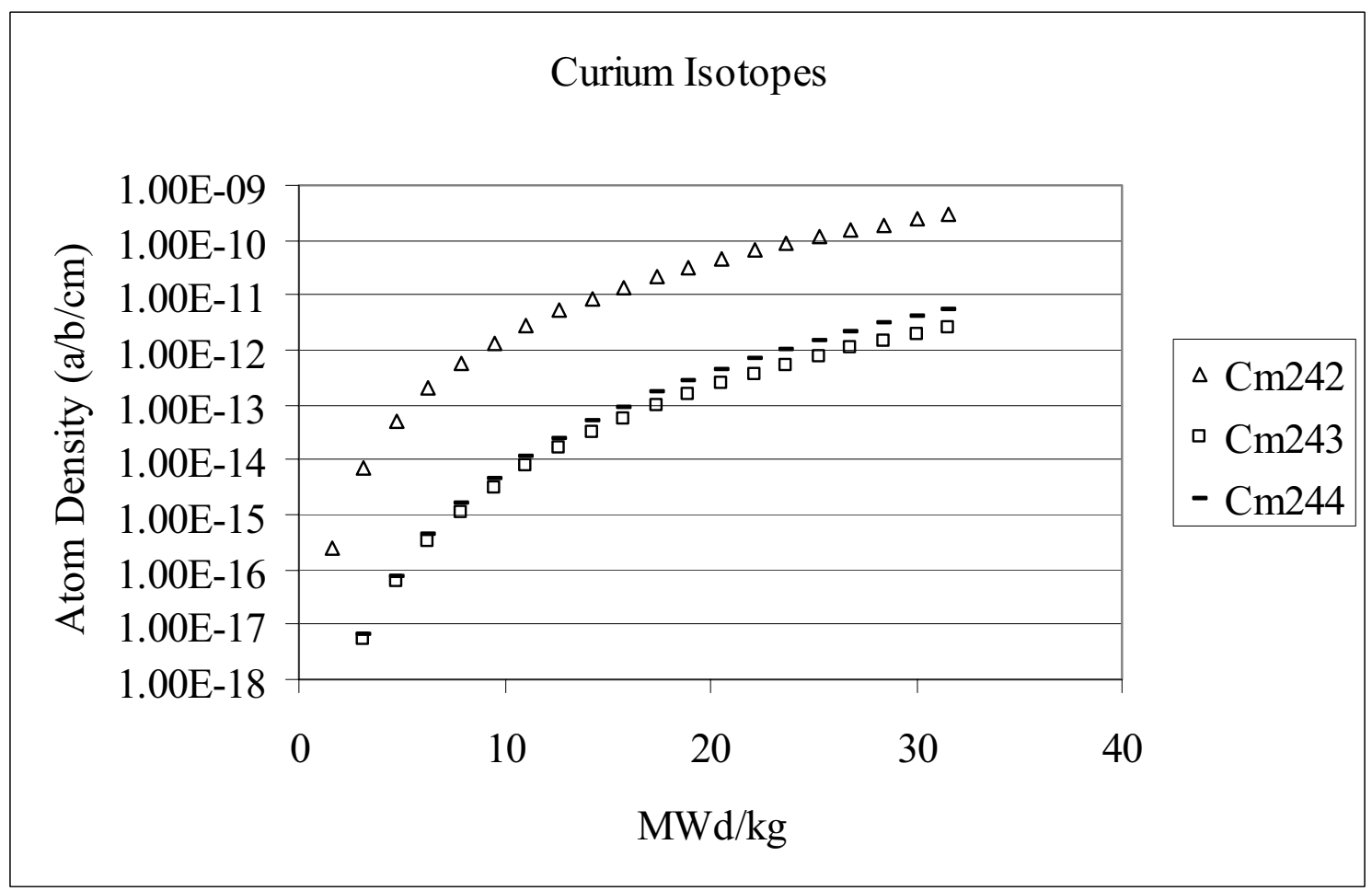

Figure 19: Change in the curium composition of the fuel vs. burn-up in the 14\% U-235 fueled model. 


\subsection{7\% Enriched Uranium Fueled Depletion Model}

The reactor specifications for the 14\% U-235 fueled depletion model are presented in Table 3. The effect of fuel burn-up on the eigenvalue of the reactor is presented in Figure 20. The increase in the eigenvalue is approximately $0.117 \Delta \mathrm{k}(0.753$ to 0.870$)$ in four years. The isotopes of uranium, neptunium, plutonium, americium, and curium are displayed in Figures 21 through 25 .

As with the $14 \% \mathrm{U}-235$ model, the uranium isotopes deplete over time with U-235 showing a significant depletion. All of the other isotopes (Np-237, Pu-238, Pu-239, Pu-240, Pu-241, Pu242, Am-241, Am-242, Am-242m, Am-243, Cm-242, Cm-243, and Cm244) increase over time and approach a steady state concentration.

Table 3: 7\% U-235 fueled Gas-Cooled Fast Reactor specifications.

Overall Core Specifications

\begin{tabular}{|c|c|}
\hline Power Density & $100 \mathrm{~W} / \mathrm{cm}^{3}$ \\
\hline Height & $1 \mathrm{~m}$ \\
\hline Radius & $1.24 \mathrm{~m}$ \\
\hline Volume & $4.83 \mathrm{~m}^{3}$ \\
\hline Total Power & $483 \mathrm{MW}$ \\
\hline \multicolumn{2}{|c|}{ Coolant Specifications } \\
\hline Coolant & $\mathrm{He}$ \\
\hline System Pressure & $7 \mathrm{MPa}$ \\
\hline Coolant Volume Fraction & $40 \%$ \\
\hline \multicolumn{2}{|c|}{ Fuel Block Specifications } \\
\hline Shape & Hexagonal prism \\
\hline Height & $10 \mathrm{~cm}$ \\
\hline Dimension across flats & $10 \mathrm{~cm}$ \\
\hline Quantity & 990 \\
\hline Fuel + Matrix Volume Fraction & $60 \%$ \\
\hline Fuel & UC \\
\hline Matrix Material & $\mathrm{SiC}$ \\
\hline Fuel to Matrix Ratio & $50 \%$ \\
\hline \multicolumn{2}{|c|}{ Fuel Constituents } \\
\hline $\mathrm{U}-234$ & $0.01 \%$ \\
\hline U-235 & $6.92 \%$ \\
\hline$U-238$ & $93.08 \%$ \\
\hline \multicolumn{2}{|c|}{ Reflector Specifications } \\
\hline Reflector Material & $\mathrm{Zr}_{3} \mathrm{Si}_{2}$ \\
\hline Axial Thickness & $1 \mathrm{~m}$ \\
\hline Radial Thickness & $1 \mathrm{~m}$ \\
\hline
\end{tabular}




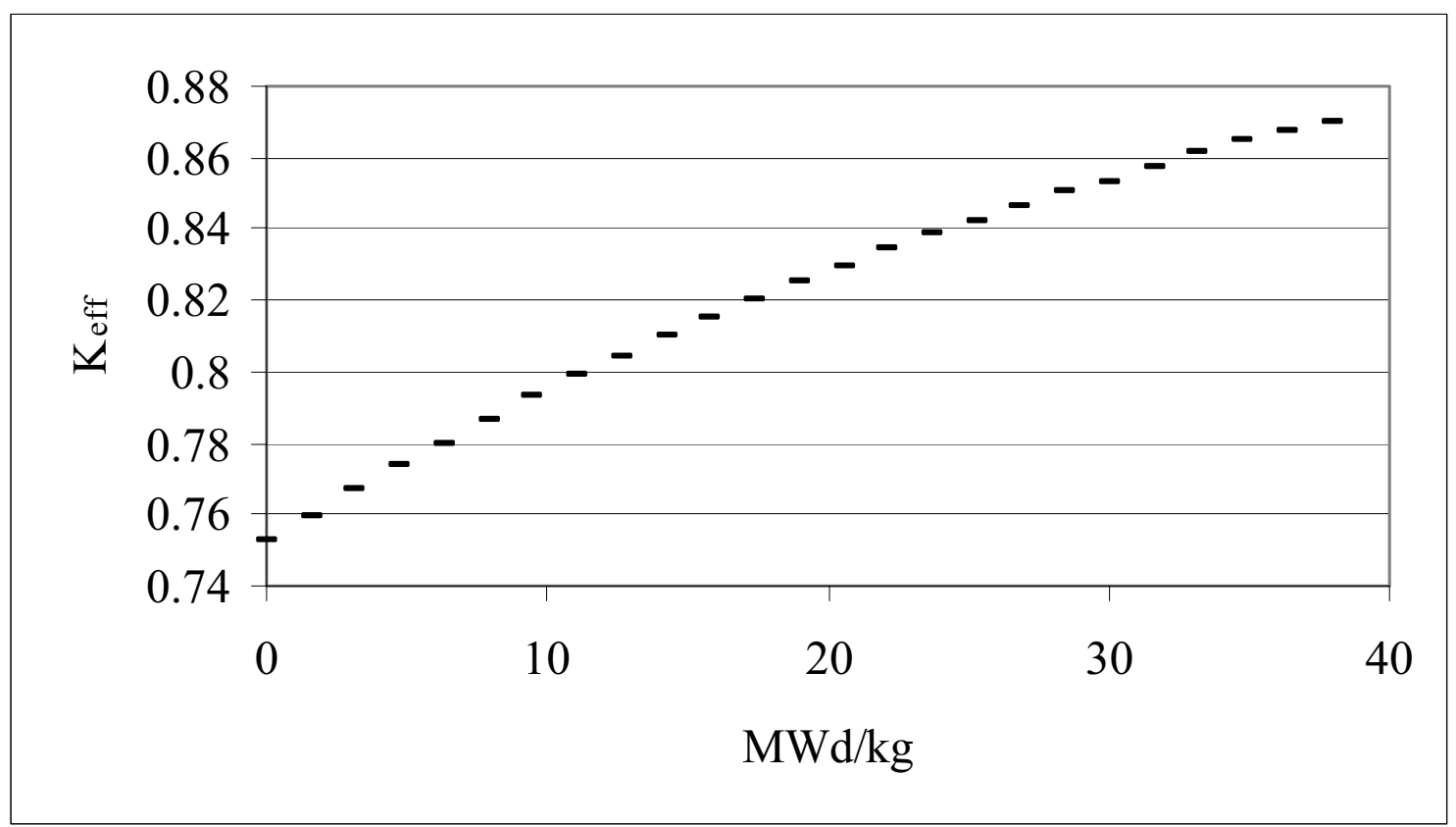

Figure 20: Change in $\mathrm{K}_{\text {eff }}$ vs. burn-up in the 7\% U-235 fueled model.

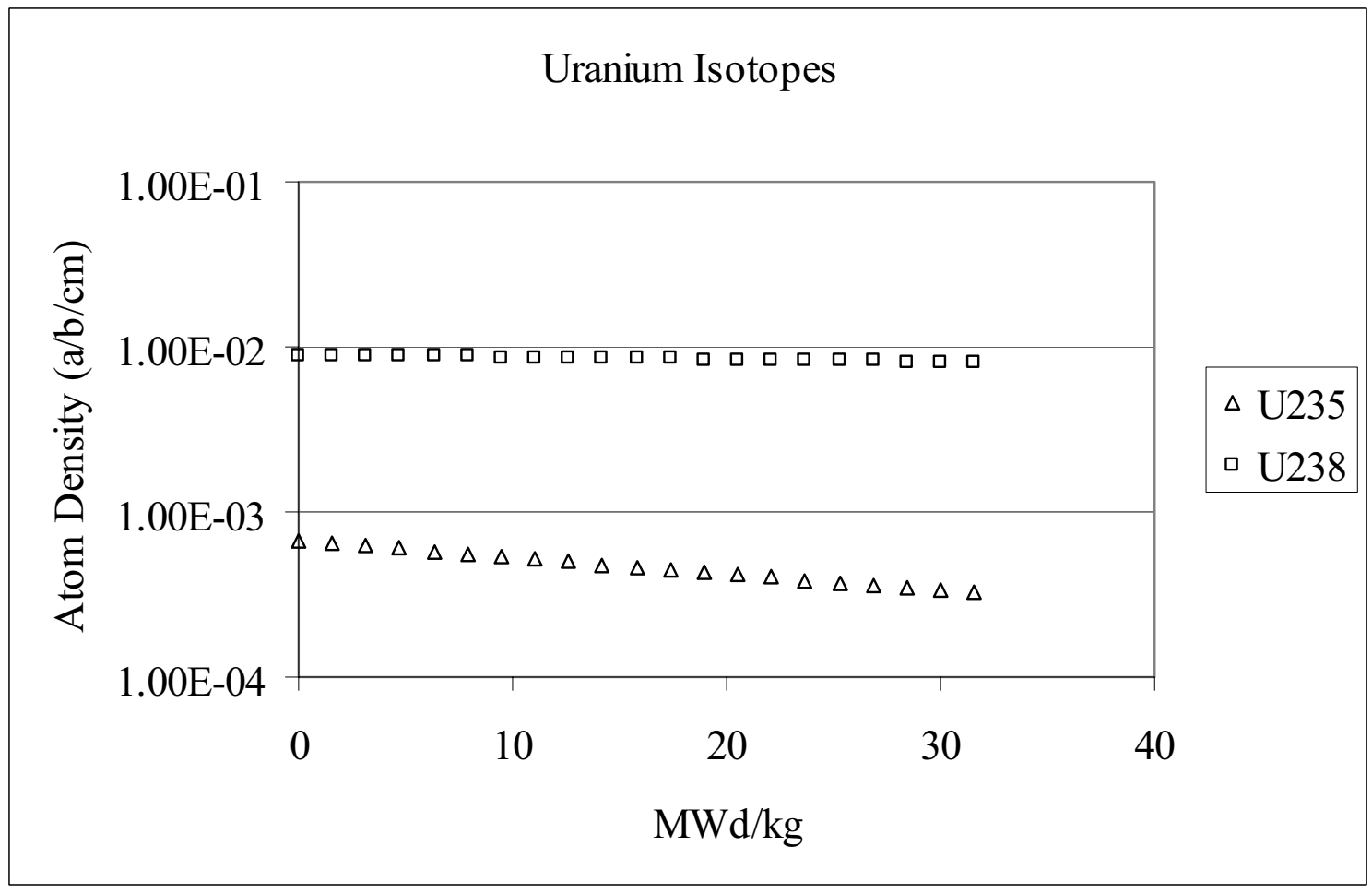

Figure 21: Change in the uranium composition of the fuel vs. burn-up in the 7\% U-235 fueled model. 


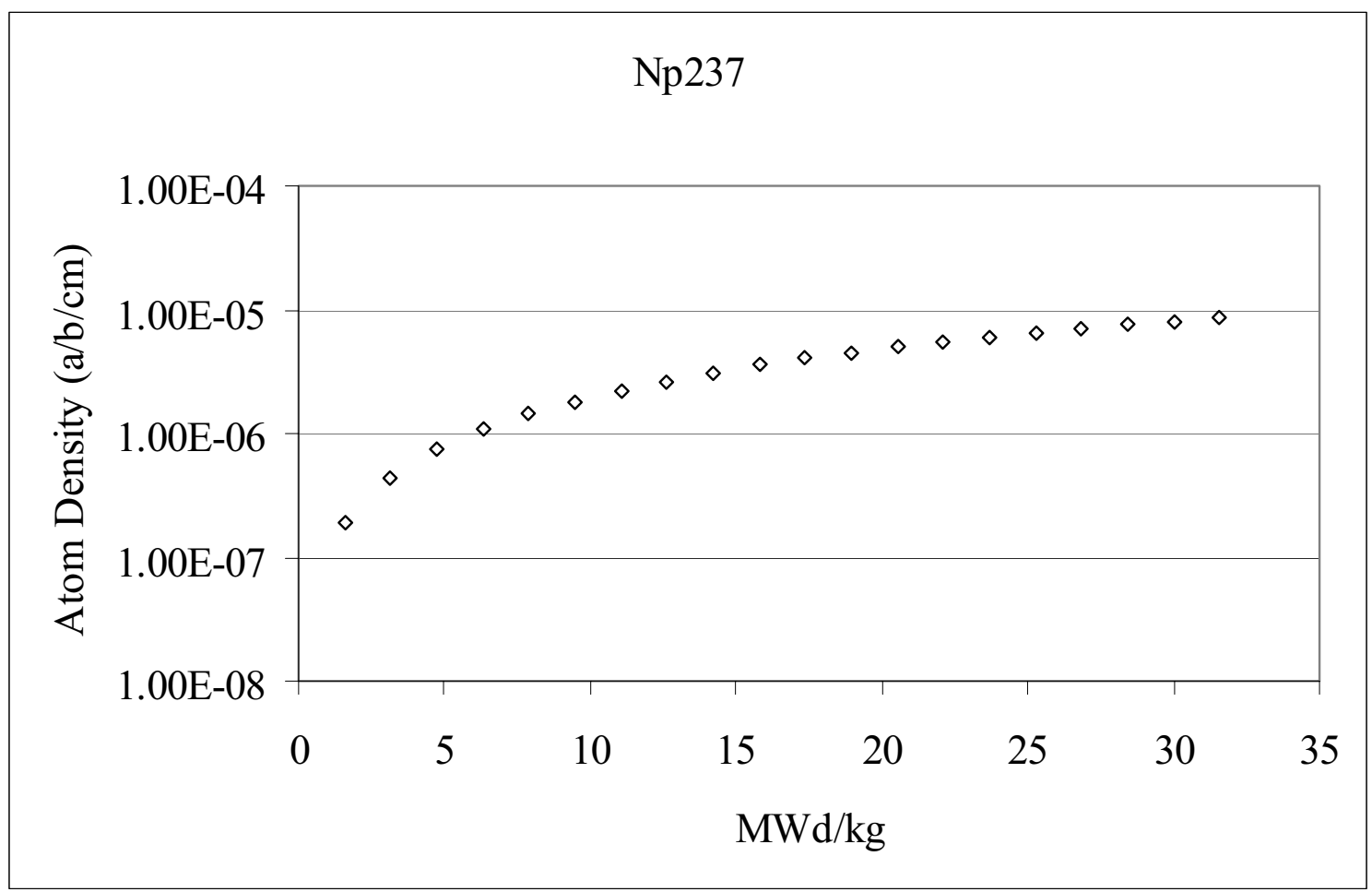

Figure 22: Change in the neptunium composition of the fuel vs. burn-up in the 7\% U-235 fueled model.

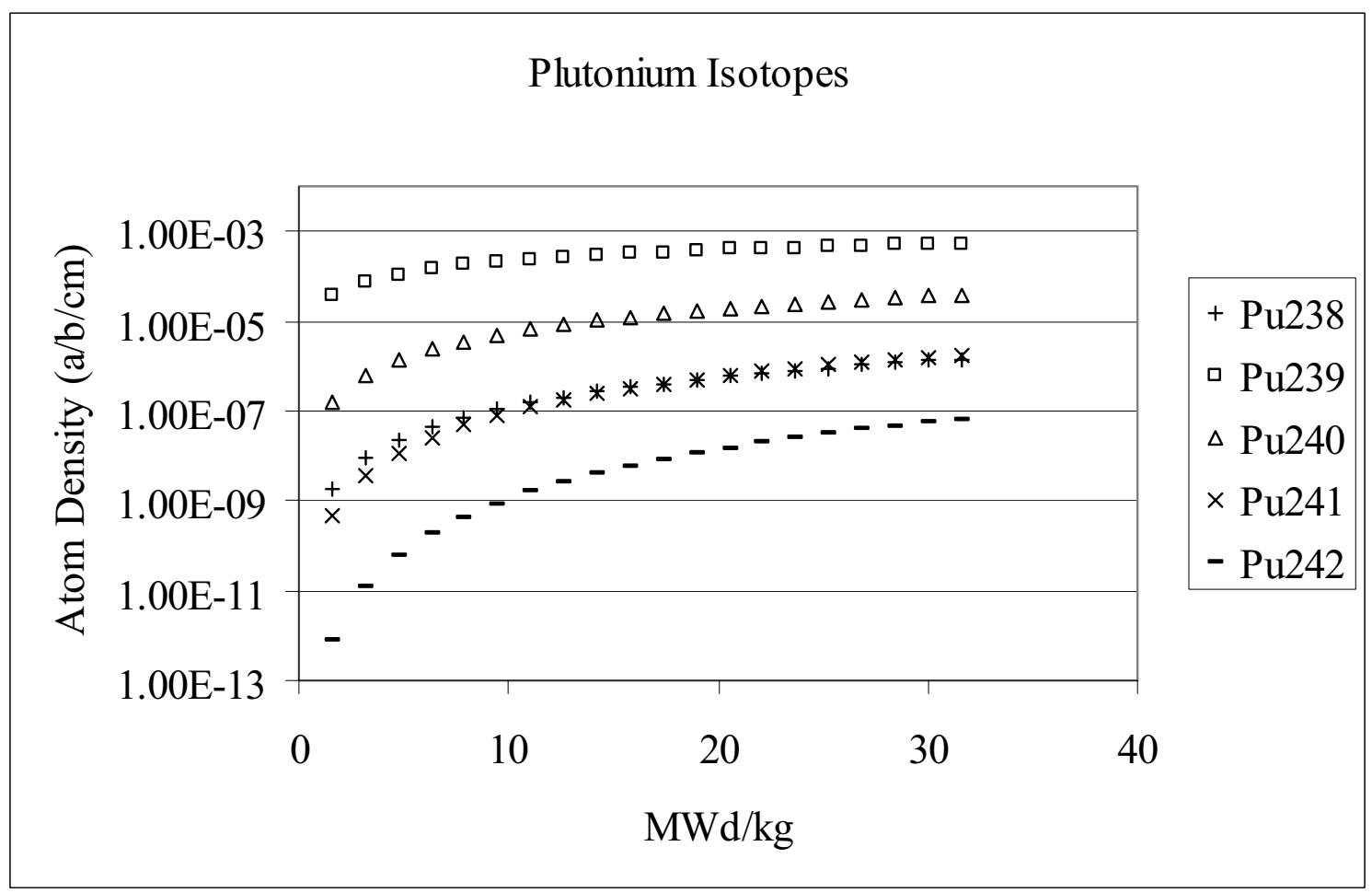

Figure 23: Change in the plutonium composition of the fuel vs. burn-up in the 7\% U-235 fueled model. 


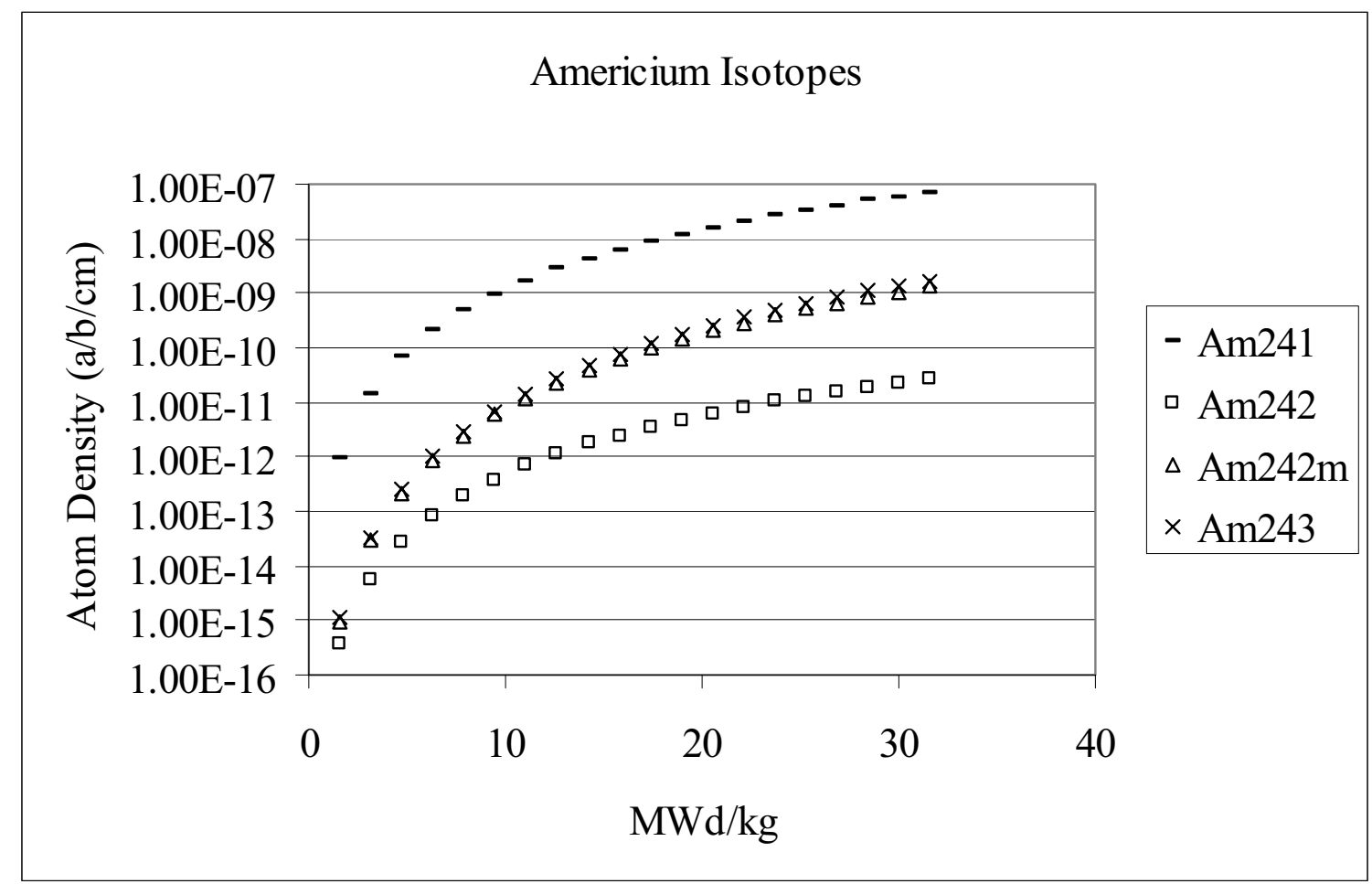

Figure 24: Change in the americium composition of the fuel vs. burn-up in the 7\% U-235 fueled model.

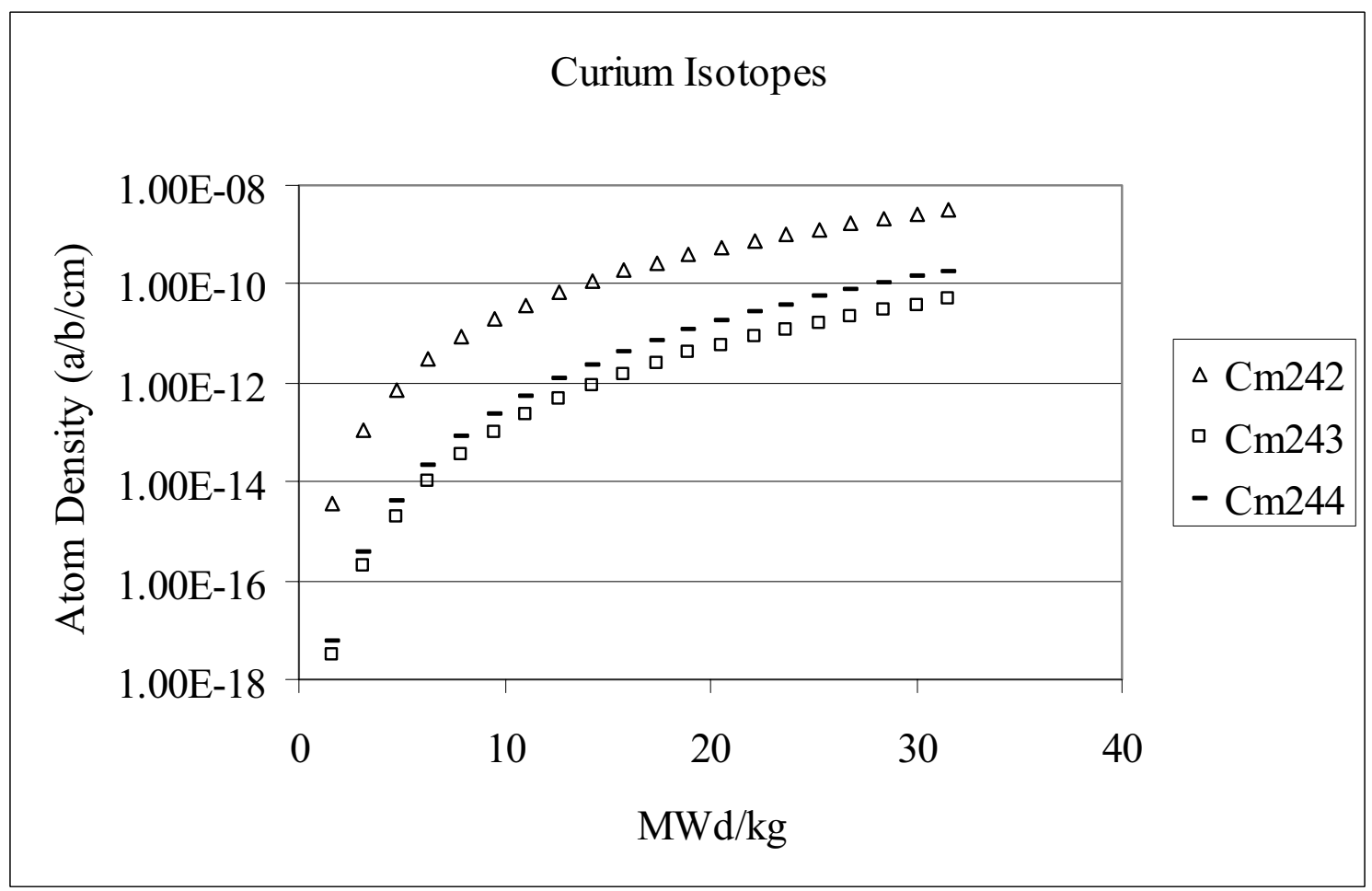

Figure 25: Change in the curium composition of the fuel vs. burn-up in the 7\% U-235 fueled model. 


\subsection{Conclusions}

The breeding capabilities of this configuration are obvious in the 7\% U-235 model and evident in both the plutonium model and the 14\% U-235 model. Changing the fuel composition from the $\mathrm{Pu}$ fuel which provided about $78 \% \mathrm{U}-238$ for breeding to the $14 \% \mathrm{U}-235$ fuel with about $86 \% \mathrm{U}-$ 238 slowed the rate of decrease in the eigenvalue a noticeable amount. Switching to the 7\% U235 fuel with about $93 \%$ U-238 showed an increase in the eigenvalue over time. The proper proportioning of U-238 to fissile material may provide a reactor with an eigenvalue that doesn't change or changes minimally over time.

Further studies to focus in on an optimal loading could include iterating on different fuel mixtures to locate the optimal mixture for a uniformly loaded core. Varying fuel mixtures in the core in zones to provide optimal usage of the neutrons in each zone and possibly decreasing the peak to average heat rate. This may provide a more uniform flux over the core and more efficient use of all the fuel in the core. Studies could also be conducted on moving fuel around the core based on its burn-up to provide zone loading of the reactor through time to again provide better use of the fuel and the neutrons in the reactor. 


\section{Tasks B and C: Core Thermal Hydraulics and Plant Design}

The goal of this research was to examine gas fast reactor thermal response during a severe offnormal scenario in which reactor decay heat is removed solely by a passive method. The offnormal scenario selected for the analysis was a simultaneous and complete double guillotine break of the primary coolant inlet and outlet ducts.

The following sections discuss an effort to create a plausible thermal hydraulics model of a prototypical gas fast reactor and perform a Loss of Coolant Analysis (LOCA), which is a Nuclear Regulatory Commission design basis accident for nuclear reactor power plants. A discussion of the thermal hydraulics analysis code is provided, along with the modeling assumptions.

\subsection{Fundamentals of the Design}

The gas fast reactor design features a "pancake" style core (height/diameter $\sim 1.7 / 2.9 \mathrm{~m}$ ) that produces $600 \mathrm{MW}$ of thermal power and has an average power density of $55 \mathrm{MW} / \mathrm{m}^{3}$. The power density is a specific point of mentioning since this value affects economics, sustainability, and safety. Economics and sustainability requirements suggest high values of power density, while safety requirements suggest the opposite.

Helium is a benign coolant choice because it has small void reactivity feedback effects, and is not subject to any change of phase. However, the hard neutron spectrum makes the VHTR TRISO fuel technology unacceptable for gas fast reactor use: i.e., the fuel density is too low, and there is poor irradiation behavior of the pyrocarbon at high dose levels. For the gas fast reactor, a refractory matrix dispersion fuel of CERCER (ceramic fuel in a ceramic matrix) appears to provide the best combination of conductivity and high temperature performance.

In the reference design, the fuel configuration is based on dispersed fuel as particles in an inert plate/block type matrix. Uranium carbide is the reference fuel, as a result of its high heavy metal density, high thermal conductivity, and anticipated minimal impact on the neutron spectrum. Unlike TRISO fuel, the gas fast reactor particle fuel will have to maximize the heavy metal content within the matrix. The matrix/cladding material is $\mathrm{SiC}$ ceramic for its high temperature properties. Figure 26 shows the prismatic plate with coolant channels within the dispersed CERCER fuel matrix, while Figure 27 presents a cutaway illustration of fuel particles in a matrix configuration. 


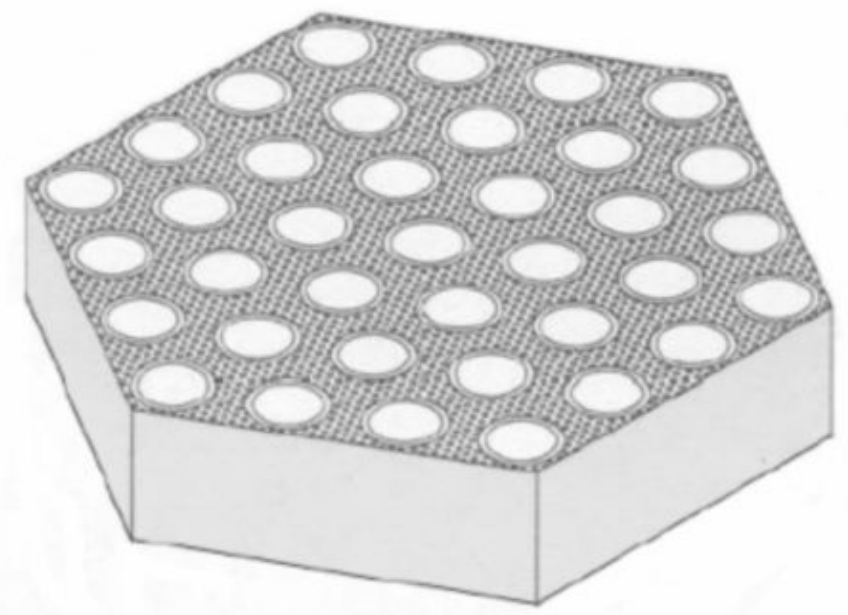

Figure 26: Schematic of a prismatic plate with dispersed fuel and coolant channels.

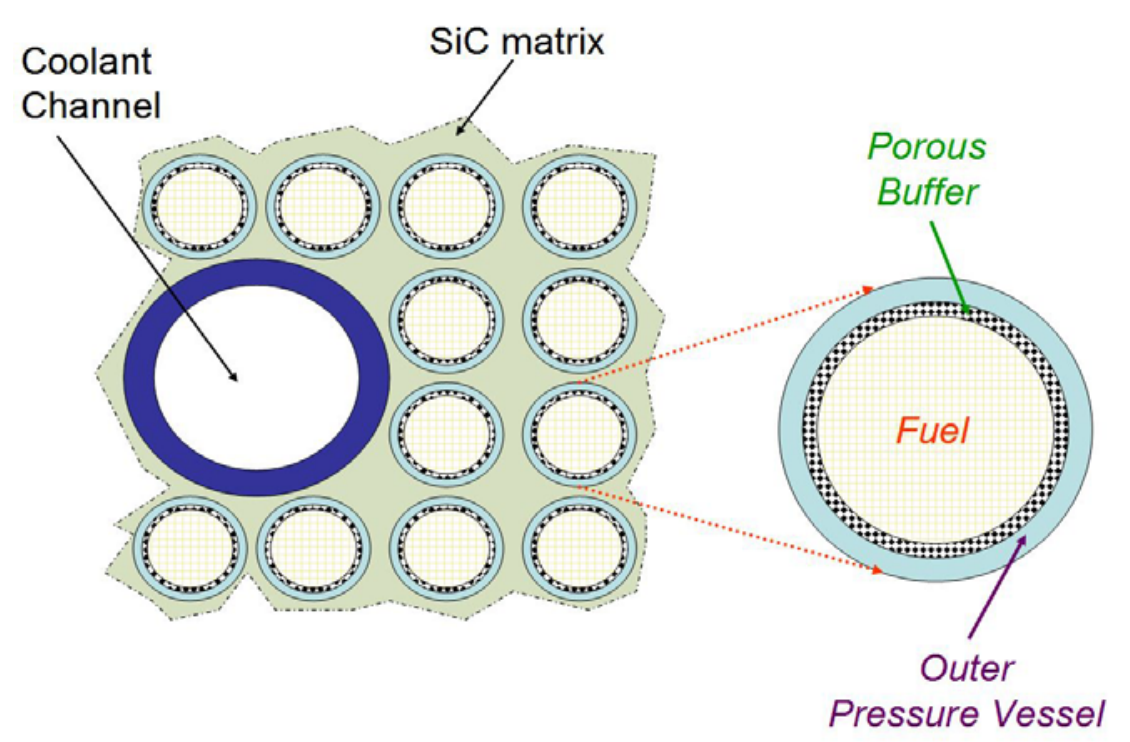

Figure 27: Cutaway of dispersed fuel plate, illustrating the components of the fuel particles and the particles placement within the fuel plate.

The reactor core in the reference design has a volume of $11 \mathrm{~m}^{3}$ and reflectors envelop the core and neutron shields in both the radial and axial directions, refer to Figure 28. The reference coolant is Helium at an outlet pressure and temperature of $7 \mathrm{MPa}$ and $850{ }^{\circ} \mathrm{C}$, respectively. It is important to note in Figure 3 that the coolant flow path is upwards through the core. 


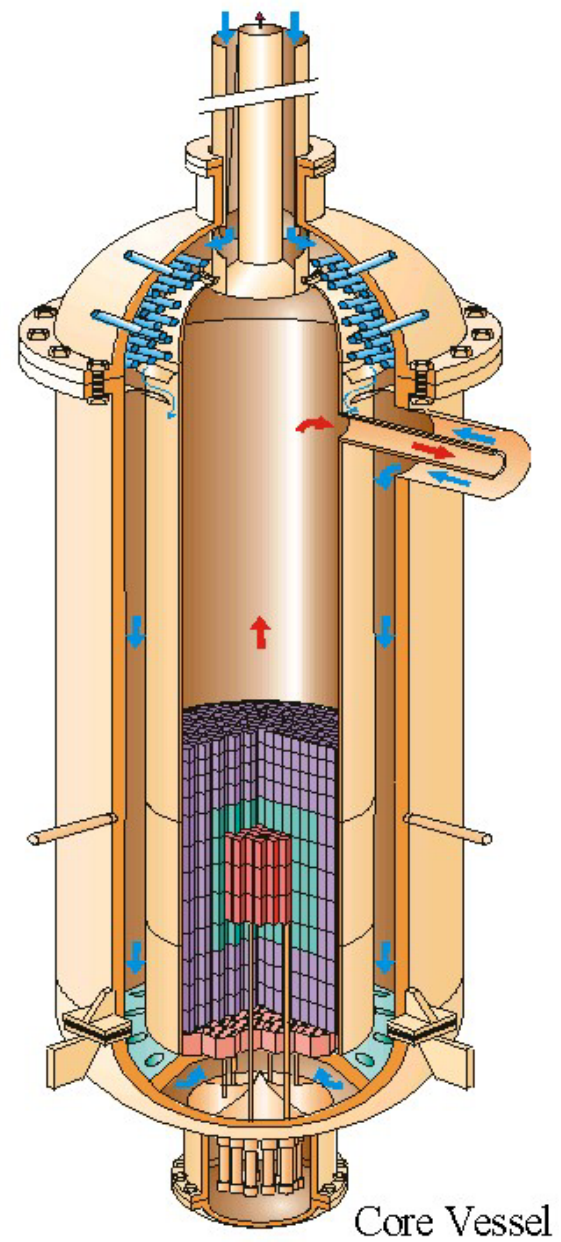

Figure 28: Prototypical reactor vessel configuration for the gas fast reactor.

The gas fast reactor has published typical operating parameters, as are presented in Table 4. 
Table 4: Design Features for the gas fast reactor concept

\begin{tabular}{|c|c|}
\hline Reactor Design Parameter & Conceptual Data \\
\hline Power plant & $600 \mathrm{MW}_{\text {th }}$ \\
\hline Net efficiency & 48\% (Helium, direct cycle) \\
\hline Coolant pressure & $9 \mathrm{MPa}$ \\
\hline Outlet coolant temperature & $850^{\circ} \mathrm{C}$ (Helium, direct cycle) \\
\hline Inlet coolant temperature & $490^{\circ} \mathrm{C}$ (Helium, direct cycle) \\
\hline Nominal flow and velocity & $330 \mathrm{~kg} / \mathrm{s}$ and $40 \mathrm{~m} / \mathrm{s}$ \\
\hline Core volume & $10.9 \mathrm{~m}^{3}(\mathrm{H} / \mathrm{D} \sim 1.7 / 2.9 \mathrm{~m})$ \\
\hline Core pressure drop & $\sim 0.04 \mathrm{MPa}$ \\
\hline Volume fraction (\%) Fuel/Gas/SiC & $50 / 40 / 10$ \\
\hline Average power density & $55 \mathrm{MW} / \mathrm{m}^{3}$ \\
\hline Reference fuel compound & $\begin{array}{c}(\mathrm{U}, \mathrm{Pu}) \mathrm{C} / \mathrm{SiC}(50 / 50 \%) \\
17 \% \mathrm{Pu}\end{array}$ \\
\hline Breeding/Burning performances & Self-Breeder \\
\hline Maximum fuel temperature & $\begin{array}{l}1174{ }^{\circ} \mathrm{C} \text { (normal operation) } \\
<1650^{\circ} \mathrm{C} \text { (depressurization) }\end{array}$ \\
\hline In core heavy nuclei inventory & 30 tons \\
\hline Fission rate (at \%); Damage & $\sim 5 \mathrm{at} \% ; 60 \mathrm{dpa}$ \\
\hline Fuel management & multi-recycling \\
\hline Fuel residence time & $3 \times 829$ efpd \\
\hline Doppler effect $\left(180^{\circ} \mathrm{C}-1200^{\circ} \mathrm{C}\right)$ & $-1540 \times 10^{-5}$ \\
\hline Delayed neutron fraction & $356 \times 10^{-5}$ \\
\hline Total He void effect & $+230 \times 10^{-5}$ \\
\hline Average burn-up rate at EOL & $\sim 5 \%$ FIMA \\
\hline Primary vessel diameter & $<7 \mathrm{~m}$ \\
\hline
\end{tabular}

MIT used the information in Table 4 in conjunction with their neutronic and thermal hydraulic analyses to create a core configuration using dispersed fuel in prismatic blocks. The MIT core for the reference design has 127 prismatic blocks with 91 coolant holes per block, and a width of $20 \mathrm{~cm}$ for each hexagonal block. An illustration of the core and its fuel blocks is shown in Figure 29. 


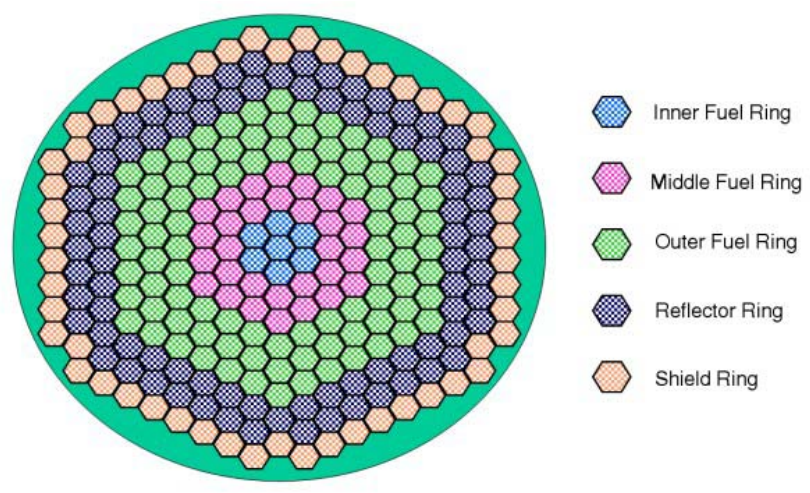

Figure 29: Illustration of the MIT core configuration for the reference design. The five radial "rings" used for creating the ATHENA model are also identified.

\subsection{ATHENA Model}

The thermal hydraulics code used to analyze the model and the simulated LOCA was the Reactor Excursion and Leak Analysis Program - 3 Dimensional (RELAP5-3D). RELAP5 was developed at the Idaho National Laboratory to allow the U.S. Nuclear Regulatory Commission to analyze postulated accidents in light water reactors. RELAP5-3D extended the RELAP5 capabilities to include 3-dimensional analyses. RELAP5-3D models neutronic and fluid flow systems and with greater than 20 years of continuous development, RELAP5-3D has become one of the premier tools for modeling off-normal events in a light water reactor. ATHENA (Advanced Thermal Hydraulic Energy Network Analyzer), complements RELAP5-3D by increasing the fluid option from water to other coolants (e.g., helium, lithium, heavy water, sodium, sodium-potassium, potassium, hydrogen, lead-bismuth, lithium-lead, nitrogen, Flibe, and carbon-dioxide). For the research discussed in this report, ATHENA version 2.24 was used.

\subsubsection{Core Analysis Radial Rings}

To create the ATHENA model for the MIT design, the core was sectioned into five radial rings. Beginning at the centerline of the core and moving in an outward radial direction, there are the inner, middle, and outer fuel rings. These three fuel rings contain the 127 prismatic blocks of the MIT design and comprise the $11 \mathrm{~m}^{3}$ volume of the core, while also satisfying the 50/40/10 volume fraction requirement for the fuel, gas, and $\mathrm{SiC}$ matrix. In Figure 29, the prismatic blocks have been colored to identify the number of blocks in each ring.

Adjacent to the outer fuel ring is the reflector ring, which is followed by the shield ring. The MIT design does not currently specify physical dimensions or void fractions for the reflector and shield blocks. Furthermore, there is an absence of details regarding the flow rate through these blocks. For this analysis, the reflector and shield blocks have the same physical dimensions as a fuel block, however, the void fraction was reduced $20 \%$ in order to provide more material for the block's respective function, i.e., neutron reflection or neutron shielding. While there are coolant channels within the reflector and shield blocks, there is no coolant flow through the reflector and shield rings. This decision was made in order to observe the heat conducted and radiated from the outer fuel ring. Since the design does not specify bypass flow between the core assemblies, this phenomenon was also ignored in the ATHENA model. 


\subsubsection{Core Unit Cell Representation}

Each of the three fuel sections (inner, middle, and outer rings) contains a predetermined number of prismatic type fuel blocks. The fuel blocks are identical in their physical dimension and fuel/coolant/matrix volume fractions. It was thus possible to create a unit cell for the fuel. The unit cell has coolant at its center, a thin layer of SiC matrix material adjacent to the coolant channel, and then a region of fuel material, see Figure 30. The dimensions for the unit cell's coolant channel diameter, matrix thickness, and fuel area are calculated from the prismatic block specifications. The unit cell method greatly simplifies the ATHENA model since the fuel, coolant, and $\mathrm{SiC}$ volumes in a fuel ring can be represented by multiplying (1) the unit cell, (2) the number of cells in a prismatic block, and (3) the number of prismatic blocks in a fuel ring.

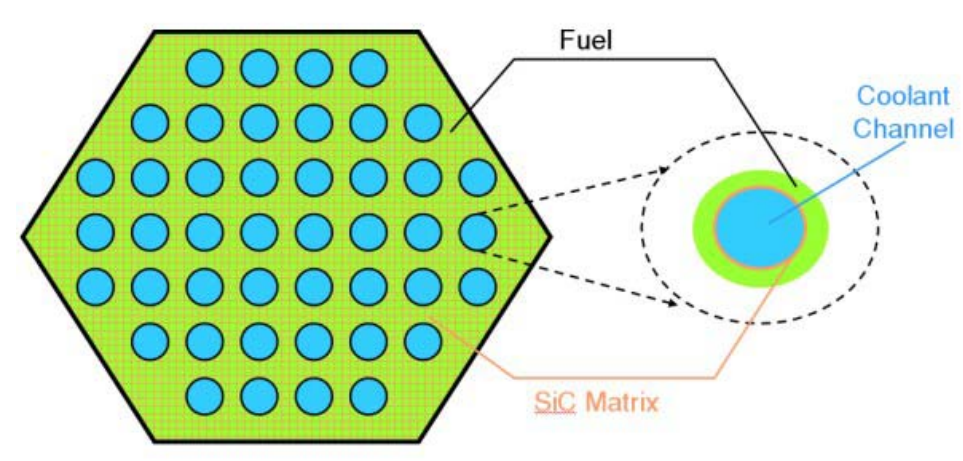

Figure 30: Fuel unit cell for ATHENA analysis.

\subsubsection{Core Materials}

The design specifies $(\mathrm{U}, \mathrm{Pu}) \mathrm{C}$ as the fuel. However, since fuel fabrication research is ongoing, these initial analyses use uranium-carbide (UC) as the fuel. A literature review revealed several variants of $\mathrm{SiC}$, this research used the properties reported by Nilsson. Pending future material development, it has been proposed that the neutron reflector is composed of titanium-nitride (TiN) and the neutron shield is manufactured from Boron-Carbide (BC). The thermal conductivity of the core materials has a significant impact on the core's thermal performance. The thermal conductivities used in the ATHENA analyses are presented in Figure 31. 


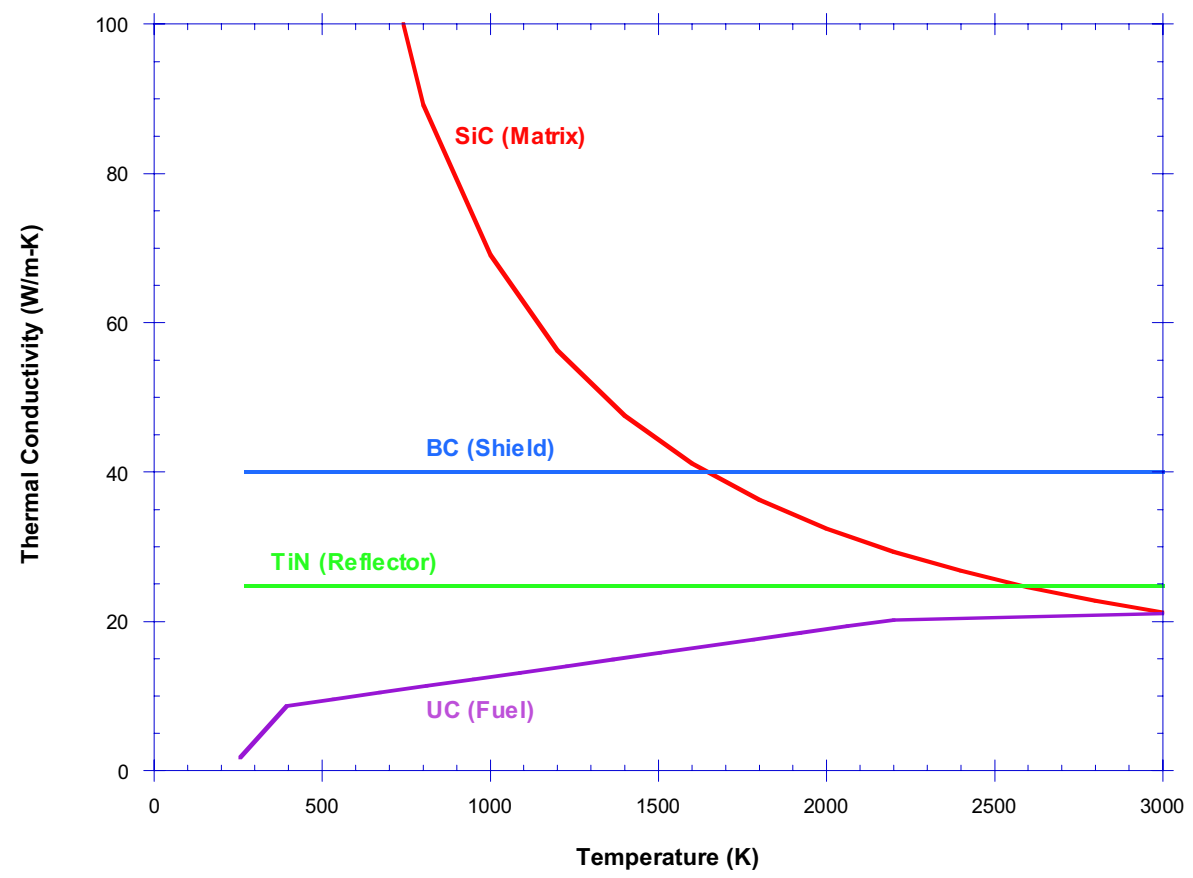

Figure 31: Thermal conductivities for the core components.

\subsubsection{Hydraulic Nodalization}

The hydrodynamic volumes of the ATHENA model were created using the prototypical reactor vessel configuration shown in Figure 28. As illustrated in Figure 32, coolant enters and exits from the top of the reactor vessel; the inlet and outlet ducts are concentric. The Power Conversion Unit (PCU) was not included in this initial analysis. Instead, inlet and outlet control volumes replace the PCU. Inlet coolant flows down the core barrel and into the inlet plenum where it is directed up through the core fuel rings. The coolant does not flow through the reflector and shield rings, as evidenced by these volumes having only a heat structure in Figure 32. A small component of the inlet flow is directed to a head plenum in order to cool the dome of the outlet plenum. After cooling the dome, the coolant flow is directed towards the inlet downcomer. The outlet plenum in the ATHENA model was scaled to match the size of the outlet plenum in Figure 28. Figure 32 shows that the ATHENA model has reflectors and shields both below and above the core, in agreement with Figure 28. Coolant flow through the core does travel through the axial reflector and shield, however, these components have zero frictional losses so they do not affect the coolant flow rate and thus the pressure drop across the core. The left side of the image in Figure 32 shows that the core assembly sits on a support structure and this structure sits on rail that is attached to the bottom of the reactor vessel. Since the core support structures can conduct heat to the reactor vessel, they are included in the ATHENA model. 


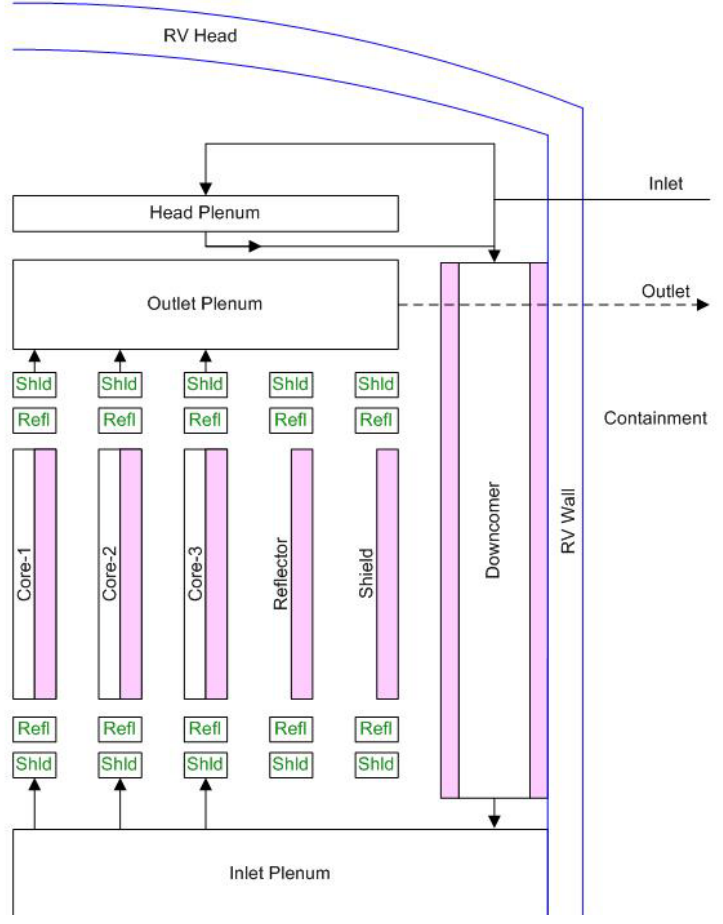

Figure 32: Schematic of the ATHENA hydrodynamic volumes that represent the prototypical in-vessel coolant circuit.

\subsubsection{Conduction and Radiation Circuits}

In the ATHENA model, heat conduction is allowed within and between the fuel rings. However, it is anticipated that convective heat transfer to the He coolant will dominate heat conduction within the fuel rings. As described earlier, heat is also allowed to conduct from the core to the axial reflector and shield. Heat from the outer fuel ring has a conduction path to the reflector ring, which in turn has a conduction path to the shield ring. The shield ring can conduct heat to the core barrel and to the core support. The selection of gap conductances for the shield ring favors conduction to the core barrel.

The outlet plenum dome is thermally conductive. However, the dome does not have a conduction path to another component. The reactor vessel is comprised of three separate volumes. The head and bottom volumes of the vessel have hemispherical heat structures. These two structures are thermally connected to the cylindrical wall of the vessel. The conduction circuit for the ATHENA model is shown in Figure 33.

The radiation circuit for the ATHENA model includes the reactor vessel wall, bottom, and head. The reactor vessel wall radiates to the cooling panels of the Reactor Cavity Cooling System (RCCS). The RCCS model was taken for an Idaho National Laboratory ATHENA model for the Very High Temperature Reactor. The vessel head and bottom independently radiate to the containment vault ceiling and floor, respectively. Both the ceiling and floor have stainless steel liners in order to prevent thermal decomposition of the containment's concrete wall. Figure 34 presents a schematic of the ATHENA radiation circuit. 


\subsubsection{Model Specifications}

The resulting ATHENA model featured 134 heat structures, 735 mesh points, and 144 hydrodynamic volumes. The primary coolant volume was $6,608 \mathrm{~m}^{3}$, while the RCCS held 815 $\mathrm{m}^{3}$ of air. As a result of their differing densities, the He mass was $9,348 \mathrm{~kg}$, while the $\mathrm{S}-\mathrm{CO}_{2}$ mass was $44,402 \mathrm{~kg}$. The air mass of the RCCS was $947 \mathrm{~kg}$.

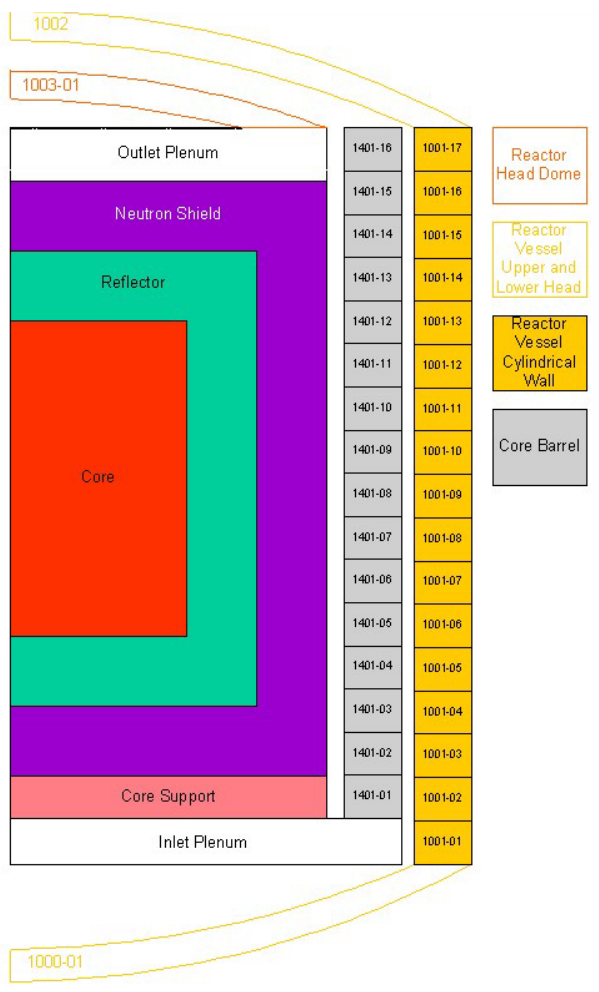

Figure 33: Schematic of ATHENA heat conduction circuit 


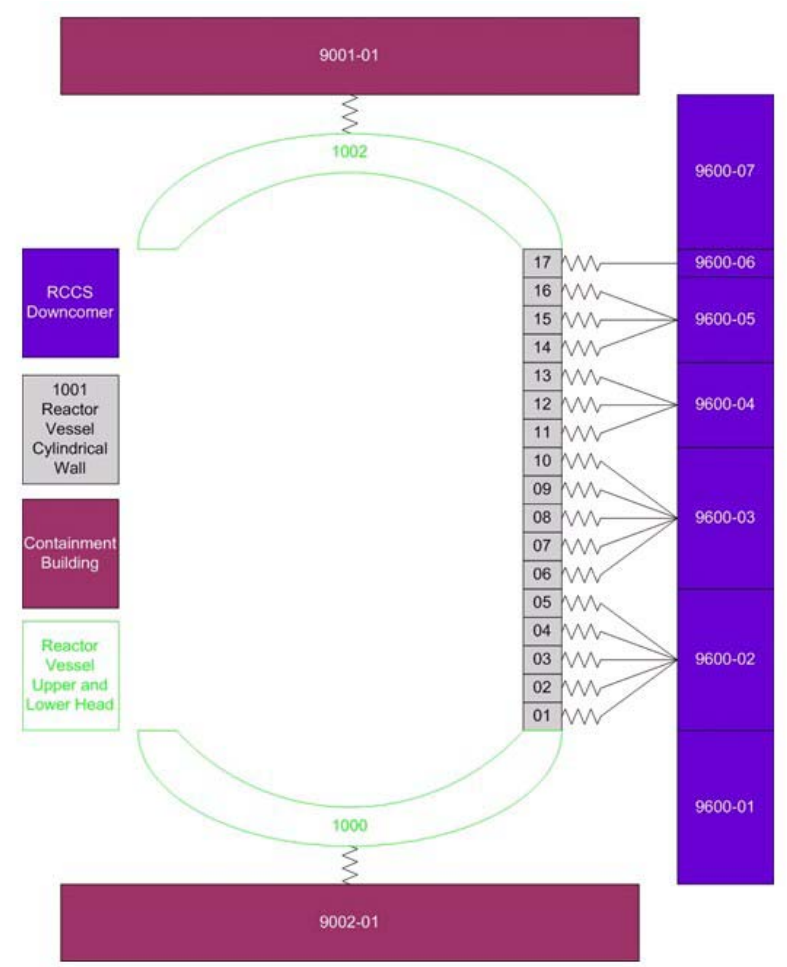

Figure 34: Schematic of radiation circuit for ATHENA model.

\subsubsection{Steady State Analysis}

The ATHENA analysis with the developed model was performed with He having the variable values provided in Table 5.

Table 5: Steady-State Coolant Parameters

\begin{tabular}{|l|c}
\hline \multicolumn{1}{|c|}{ Coolant Parameter } & He Option \\
\hline Inlet Temperature $\left({ }^{\circ} \mathrm{C}\right)$ & 490 \\
\hline Outlet Temperature $\left({ }^{\circ} \mathrm{C}\right)$ & 842 \\
\hline Mass Flow Rate $(\mathrm{kg} / \mathrm{s})$ & 330 \\
\hline Outlet Pressure $(\mathrm{MPa})$ & 7 \\
\hline
\end{tabular}

The mass flow rate was determined through the use of a control variable. The control variable adjusted the flow into the inlet plenum until the prescribed temperature in the outlet plenum was attained. This procedure was employed in order to verify the pressure drop across the core, as it was reported in the MIT design.

The RCCS is supplied with atmospheric air at $20^{\circ} \mathrm{C}$ from the top of the containment vault. Using draft airflow, the RCCS panels absorb the radiated heat from the reactor vessel and direct the heated air upwards, where it is rejected to the atmosphere external to the containment. 
As discussed earlier, there was neither gamma nor neutron heating in the reflectors or shields. Any temperature rise in these components was the result of thermal conduction or radiation from the core. Steady-state operation, in terms of constant material temperatures, was determined by observing the air temperature of the containment vault. As a result of the radiation and conduction from the core components and the radiative heat being removed by the RCCS, the reactor vessel wall required an analysis time of 5.3 days in order to achieve steady state heating of the containment vault. The analysis time is the length of the analysis simulation and is different from the computer processing time.

\subsection{Simulated LOCA Analysis}

The LOCA analysis had the objective of simulating a simultaneous double guillotine break of the inlet and outlet coolant ducts. A control valve was installed in each of the coolant ducts. The valves shared the respective flow areas of the coolant ducts. When the loss of coolant transient is initiated, both control valves instantaneously block flow to the outlet control volume and from the inlet control volume. Flow from the reactor vessel inlet and outlet cooling ducts is allowed to escape into the containment vault.

Simultaneous with the flow control valve operation, the reactor core is SCRAMed. In order to accomplish the SCRAM, a SCRAM reactivity curve from the Seabrook Pressurized Water Reactor (PWR) was input to the ATHENA model. It was recognized that a PWR has a thermal neutron spectrum while the gas fast reactor has a fast neutron spectrum. However, for these initial analyses, the Seabrook PWR SCRAM reactivity curve was considered to be within an acceptable margin of error, given the current design status. The analysis time following the loss of coolant initiation was $50 \mathrm{hrs}$.

\subsubsection{Evolution of the ATHENA Model}

With time, the ATHENA model evolved to better represent an actual reactor and to incorporate improvements in the modeling technique. For space consideration, only the major improvements to the model are discussed below. In order to minimize confusion regarding the current state of the model, only the most recent plots of the LOCA response are presented.

\subsubsection{Heat Transfer Correlations}

The initial ATHENA model used the Dittus-Boelter heat transfer coefficient correlation for turbulent flow. However, MIT analyses suggested that the Gnielinski correlation was better for helium forced convection cooling. Thus, one of the goals for this research was to observe the predicted fuel temperatures, when the Dittus-Boelter and Gnielinski correlations were individually selected.

Table 6 presents the steady-state temperatures of the five axial fuel cells for both the DittusBoelter and Gnielinski analyses. It is observed in Table 6 that the peak fuel temperature occurs at axial cell 3, which corresponds to the peak power distribution. More importantly, Table 6 illustrates that the Gnielinski correlation is more conservative in its prediction of helium's ability 
to transfer heat from the coolant wall. The difference in resulting fuel temperatures for the two correlations is also presented in Table 6.

Table 6: Difference in Dittus-Boelter and Gnielinski-produced Axial Fuel Temperatures

\begin{tabular}{|c|c|c|c|}
\hline $\begin{array}{c}\text { Axial Fuel Cell } \\
\text { Number }\end{array}$ & $\begin{array}{c}\text { Dittus-Boelter } \\
\text { (C) }\end{array}$ & $\begin{array}{c}\text { Gnielinsk } \\
\mathbf{i} \text { (C) }\end{array}$ & $\begin{array}{c}\text { \% } \\
\text { differenc } \\
\mathbf{e}\end{array}$ \\
\hline 1 & 721 & 748 & +3.7 \\
\hline 2 & 1116 & 1223 & +9.6 \\
\hline 3 & 1330 & 1462 & +9.9 \\
\hline 4 & 1300 & 1388 & +6.8 \\
\hline 5 & 1029 & 1051 & +2.1 \\
\hline
\end{tabular}

The simulated LOCA was performed in order to observe the fuel temperatures resulting from the two heat transfer correlations. Figure 35 presents the LOCA-induced fuel temperatures for using the two heat transfer correlations.

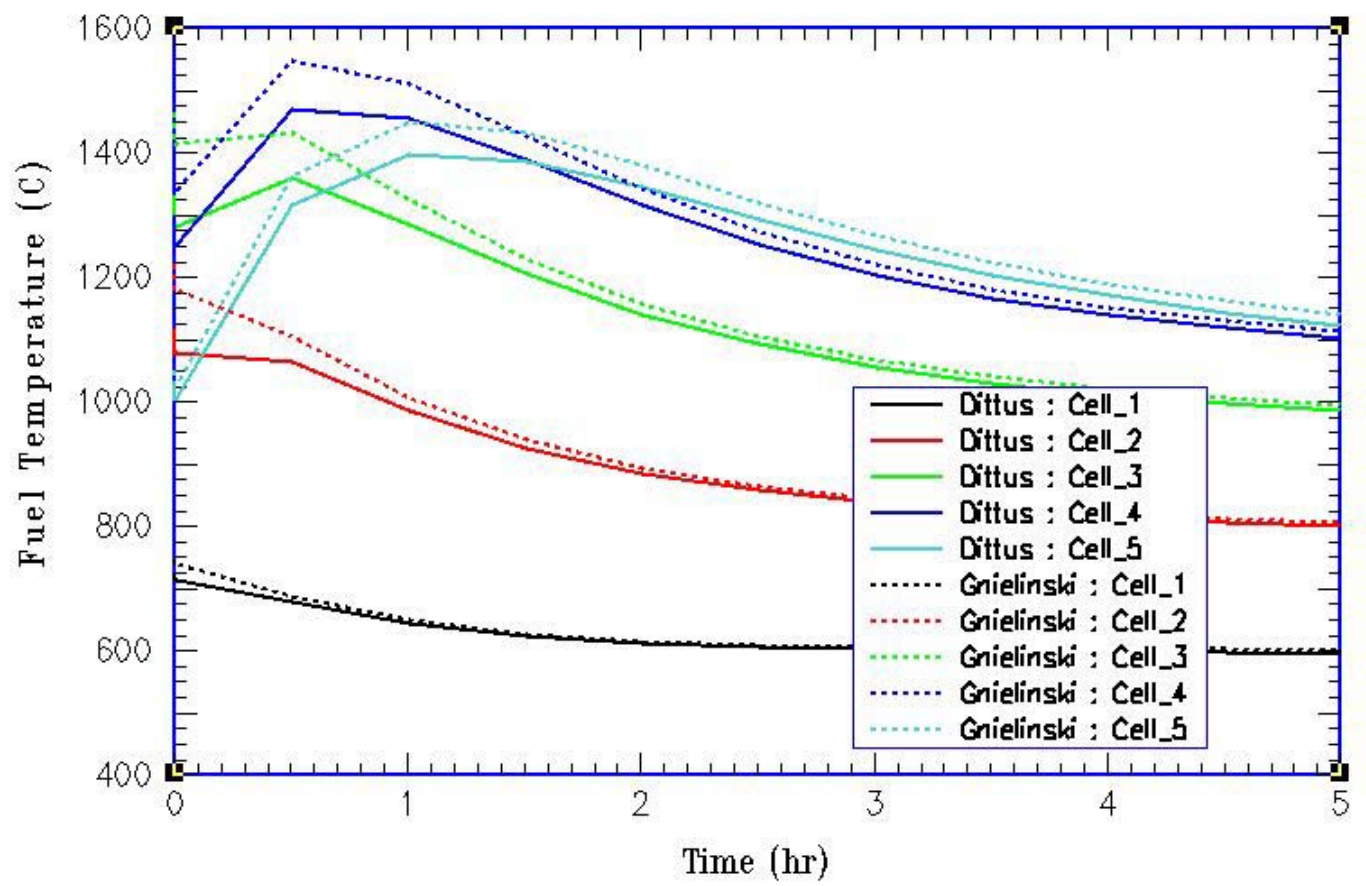

Figure 35: Comparison of LOCA axial fuel temperatures for the Dittus-Boelter and Gnielinski correlations

In Figure 35, the change in slope of the fuel temperature is a result of the guard containment vent valves opening to release guard containment in excess of the pre-determined 1.2 MPa. The valves open when the LOCA is initiated and again when the heat removed from the core increases the cavity's pressure. The guard containment pressure for this analysis is shown in Figure 36. It is this backpressure that gives the helium-air mixture sufficient density to remove 
the reactor decay heat without exceeding the fuel design limit of $1650{ }^{\circ} \mathrm{C}$. It is interesting to note in Figure 36 that during the first 1.5 hours of the transient, the guard containment pressure is nearly the same, regardless of the heat transfer coefficient used.

It is observed in Figure 35 that the fuel temperatures resulting from the Gnielinski correlation are considerably different from those resulting from the Dittus-Boelter correlation. Within the first two hours of the transient, the fuel temperature predicted using the Gnielinski correlation does not provide a significant safety margin from the design limit of the fuel. For this reason, the Gnielinski correlation is considered to be more conservative and was thus selected as the default heat transfer correlation for future analyses. That is, a design that provides an acceptable safety margin when the Gnielinski correlation is used will be more conservative than a design that has the same safety margin, but is based on the Dittus-Boelter correlation.

The results presented in Figure 37 were not often discussed in existing LOCA analyses found in the literature. However, Figure 37 is very important because it shows that while natural circulation with a back pressure of $1.2 \mathrm{MPa}$ is sufficient to remove the reactor decay heat, the resulting gas temperature in the guard containment will present severe challenges to the reactor and its supporting materials. Regardless of the heat transfer coefficient used, a guard containment temperature above $500{ }^{\circ} \mathrm{C}$ will mostly likely be an obstacle for reactor licensing. The steady-state guard containment temperature is $242{ }^{\circ} \mathrm{C}$.

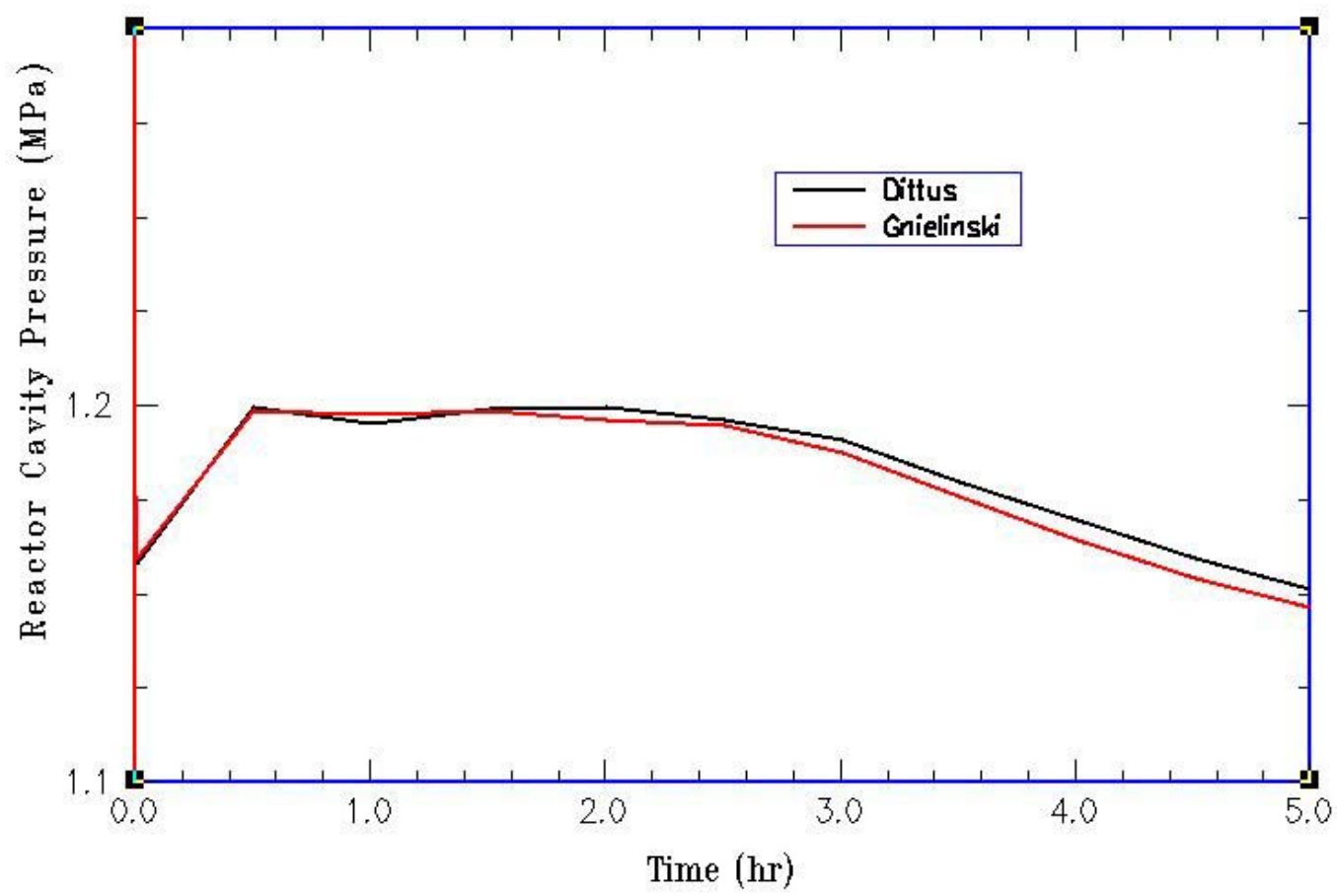

Figure 36: Guard containment pressure during the simulated LOCA with the Dittus-Boelter and Gnielinski correlations 


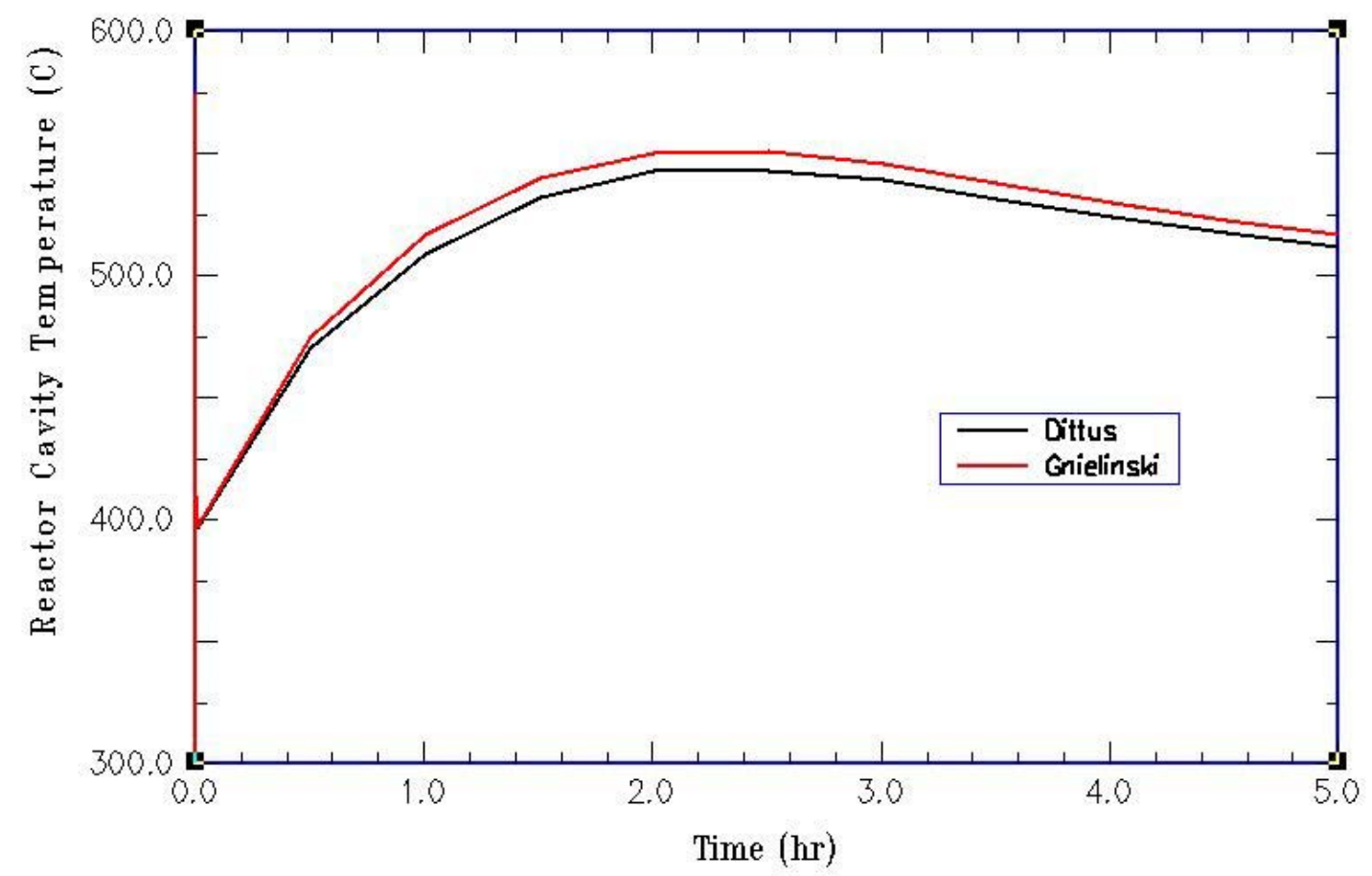

Figure 37: Guard containment temperature during the simulated LOCA with the Dittus-Boelter and Gnielinski correlations

\subsubsection{Influence of Guard Containment Back Pressure}

Given the results in Figure 37, the question arose whether a higher backpressure would decrease the guard containment temperature since it was known that the higher backpressure would reduce fuel temperatures. If the higher backpressure would also reduce the guard containment temperature, then it might offset the additional cost of a higher pressure-qualified guard containment.

Figure 38 presents the resulting fuel temperature for axial fuel cell 4 when the Gnielinski correlation is used and the backpressure is increased to 2 and $3 \mathrm{MPa}$. It is observed in Figure 38 that the fuel temperature is no longer a concern at the higher guard containment backpressures. Unfortunately, the higher guard containment back pressure is more efficient at removing decay heat from the reactor core, but it simply moves this heat from the core and into the guard containment, as shown in Figure 39. That is, the heating rate and level of the guard containment increase with increasing back backpressure.

\subsubsection{Water Decay Heat Removal Loop}

It was hypothesized that the addition of a natural circulation water-cooled Decay Heat Removal Loop (DHRL) would provide an advantage of a lower guard containment temperature while maintaining the $1.2 \mathrm{MPa}$ backpressure of the base case.

A generic DHRL was created using a piping loop, pressurizer for the loop, pool of water mounted on top of the containment building, and two heat exchangers (refer to Figure 40). A 6 
$m$ length finned heat exchanger was attached to the lower loop section that resided within the guard containment. The upper loop section had two $4 \mathrm{~m}$ length vertical finned heat exchangers that were submerged in the containment top-mounted water pool. The difference in height between the upper and lower heat exchangers, in addition to one side of the loop having a longer length, resulted in the establishment of natural circulation within the DHRL loop.

The water pool atop the containment building served as a heat sink and this pool was allowed to evaporate water to the air atmosphere external to the containment building. The initial temperature and pressure of the pool were $20{ }^{\circ} \mathrm{C}$ and $0.1 \mathrm{MPa}$, respectively. The DHRL pressurizer maintained a pressure of $4 \mathrm{MPa}$ in the piping loop. The initial temperature of the water in the loop was $20^{\circ} \mathrm{C}$. During the LOCA transient, natural circulation in the DHRL established an average flow rate of $10 \mathrm{~kg} / \mathrm{s}$ or $0.2 \mathrm{~m} / \mathrm{s}$.

Figure 41 presents the resulting fuel temperatures for the DHRL analysis. The figure includes temperatures for the base Gnielinski case and the Ginielinski model with the DHRL. It is observed in Figure 41 that the fuel temperature for the DHRL case exceeds the design temperature limit of $1650{ }^{\circ} \mathrm{C}$. The higher fuel temperatures for the DHRL case suggest that the guard containment temperatures and pressures are less than the values for the base Gnielinski case. Figure 42 indeed reveals that the DHRL case has a considerably lower guard containment temperature.

The prospect of using a high backpressure in the reactor cavity to maintain heat transfer efficiency during a LOCA seems very promising. The simple physics is that by maintaining a high density of the air-helium mixture, one can adequately remove the decay heat from the reactor without any active systems. However, the Ideal Gas Law intervenes and when the backpressure of the guard containment increases while maintaining the same volume, the temperature of the guard containment likewise increases.

It was imagined that a simple solution would be to add cooling to the guard containment so that the material within the guard containment did not suffer integrity losses due to the high thermal loading. It was simple to add a passive water loop that used natural circulation to remove a considerable amount of heat from the guard containment during the LOCA transient. However, the fundamental law was still in place: if you decrease the guard containment temperature, you consequently decrease the pressure, which lowers your gas density and negatively impacts its capacity to remove heat from the reactor. 


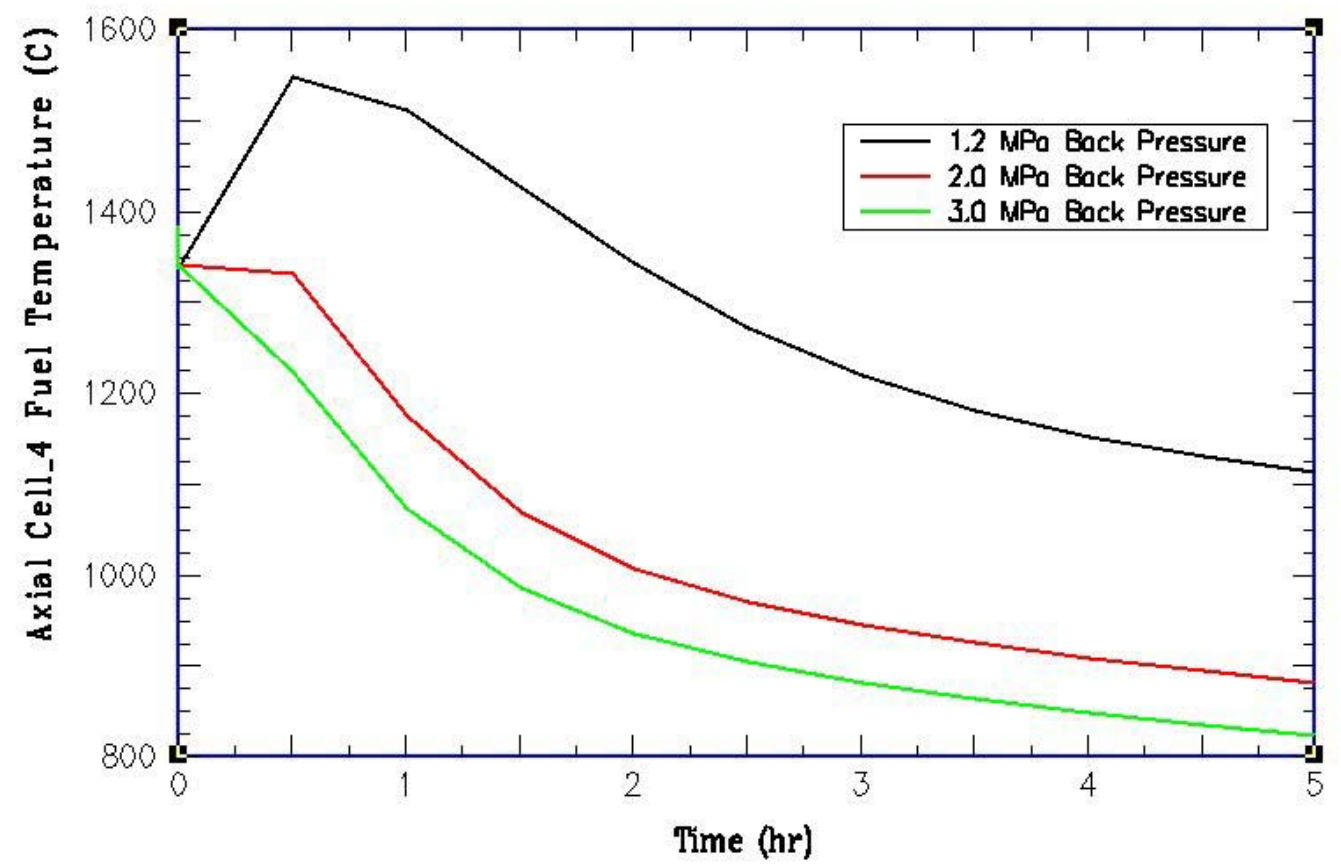

Figure 38: Fuel temperature as a function of increased guard containment backpressure. 


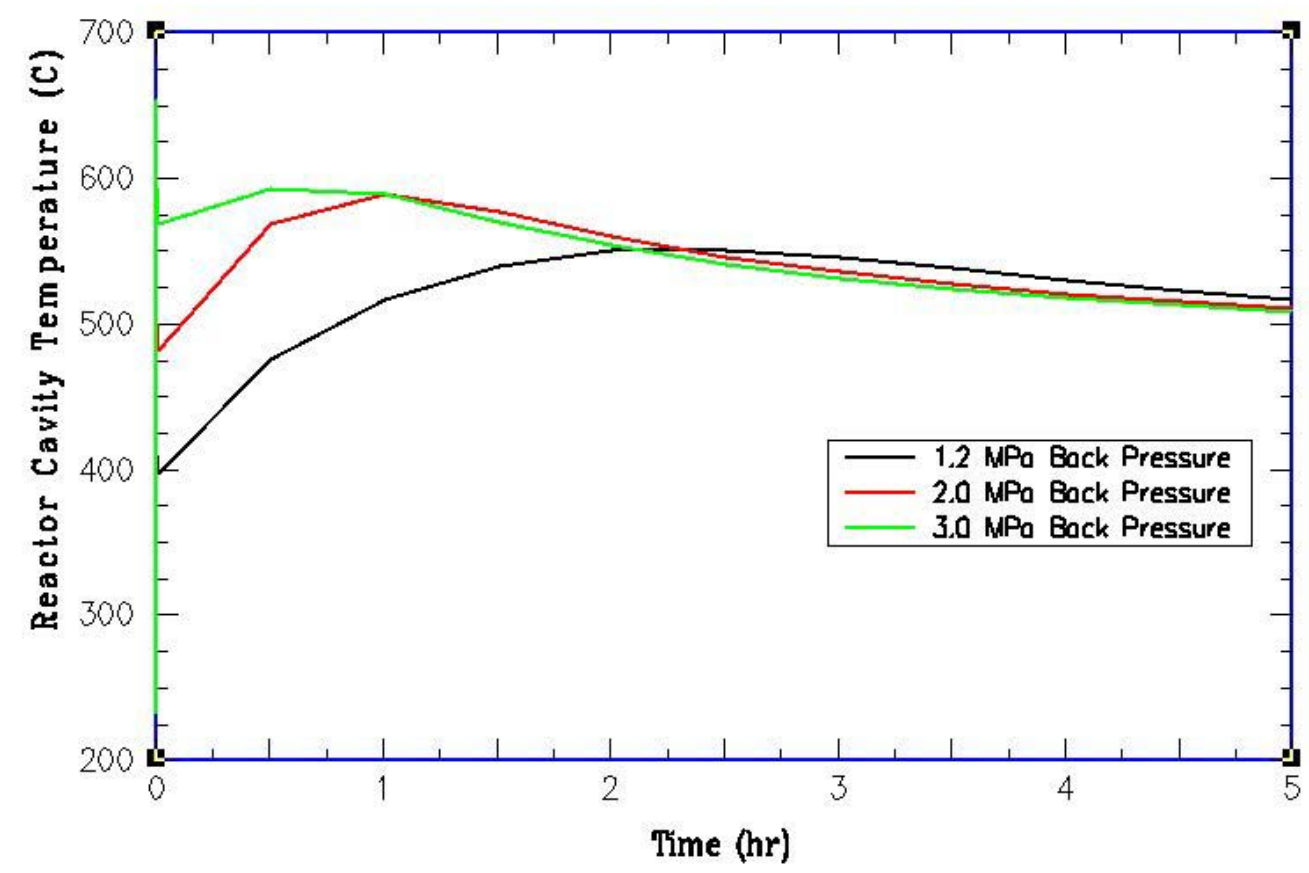

Figure 39: Guard containment temperature as a function of increasing backpressure.

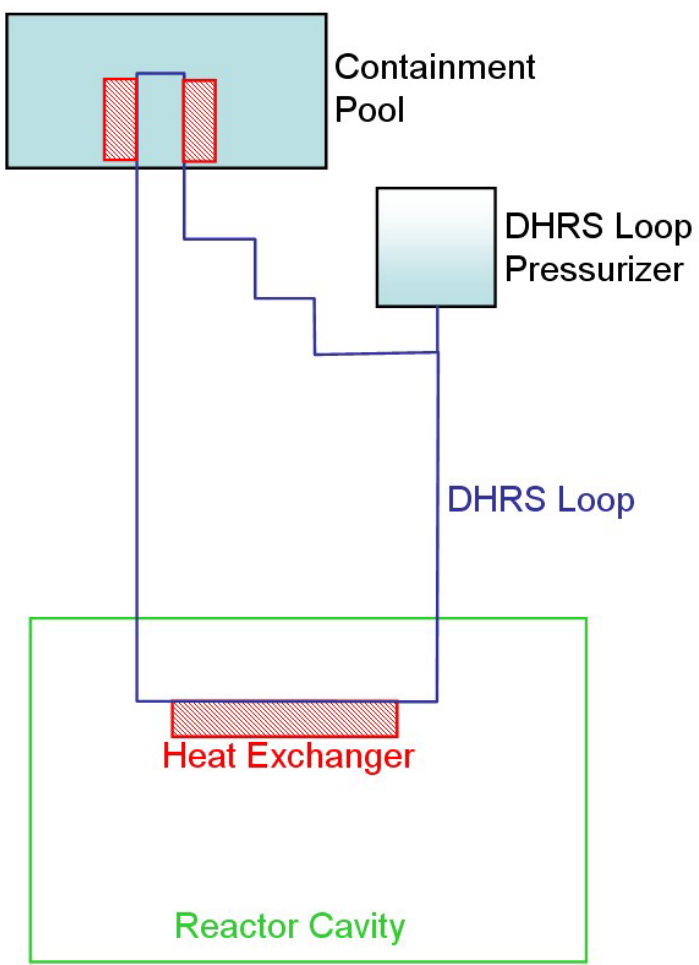

Figure 40: Schematic of natural convection water-filled decay heat removal loop 


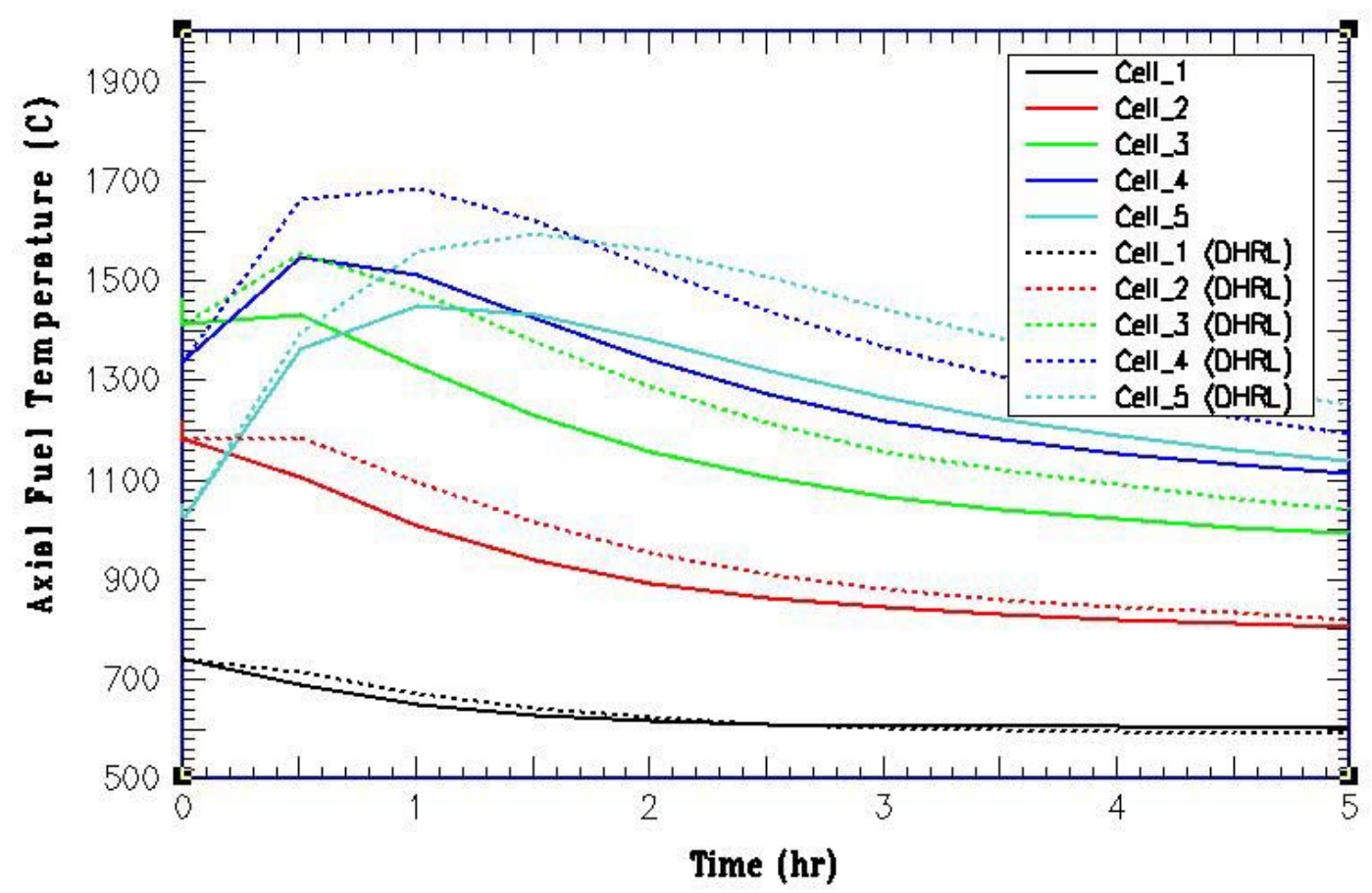

Figure 41: Fuel temperature with and without natural circulation water-filled decay heat removal loop

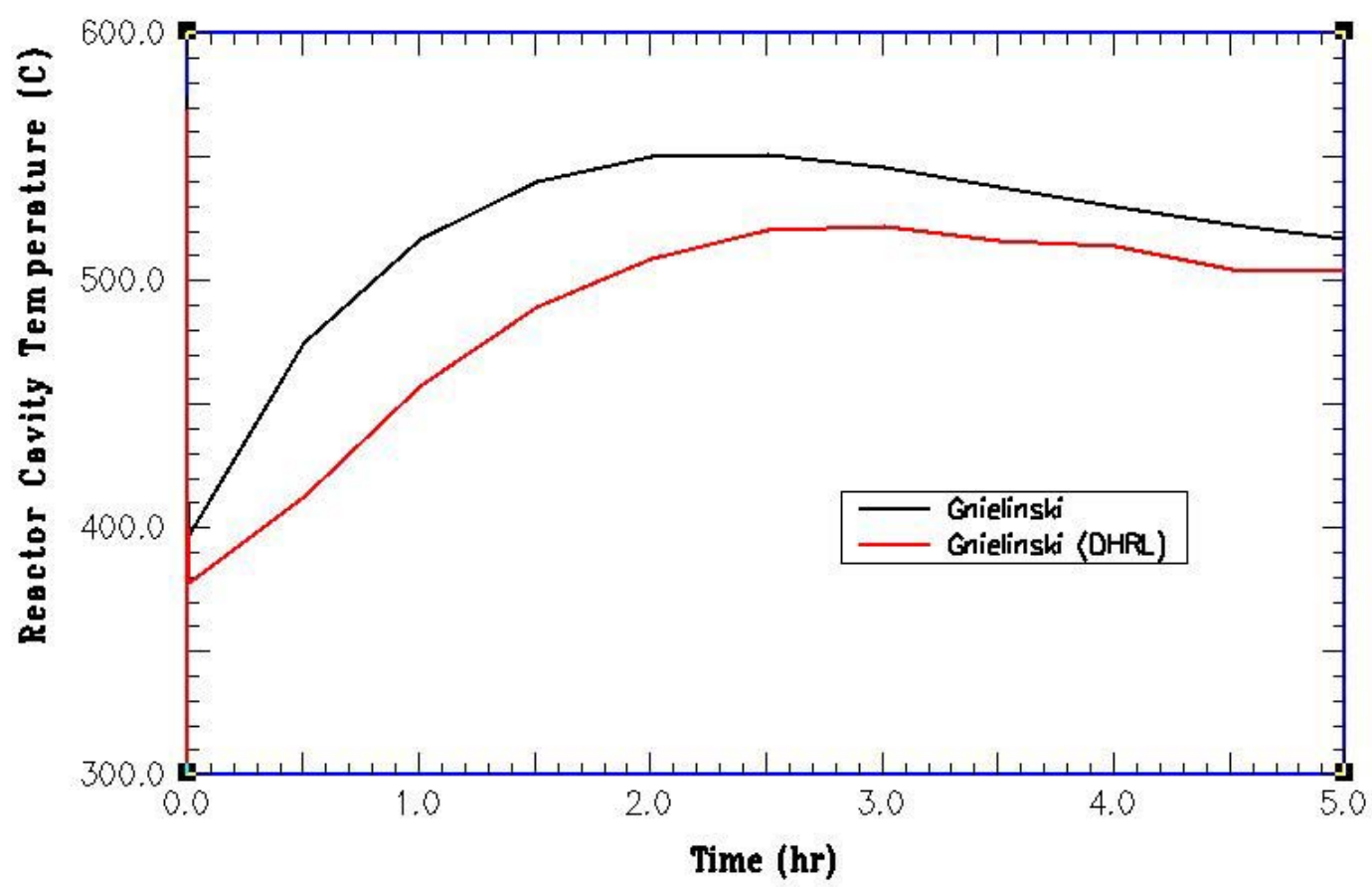

Figure 42: Guard containment pressure with and without natural circulation water-filled decay heat removal loop 


\subsubsection{Radial Peaking Factor}

The initial ATHENA model included a core axial height of $1.7 \mathrm{~m}$. The model divides this height into five axial cells and an axial power profile that has a cosine distribution with a peaking factor of 1.25. A schematic of the axial fuel cells and the axial power distribution is shown in Figure 43. It was understood that the assumption of a flat radial profile and the omission of hot channels within the core would yield optimistic results. Thus, a peaked radial profile of 1.3 was added to the model. The addition of this radial profile caused the steady-state analysis to produce fuel temperatures that exceeded the design basis. To compensate for this effect, flow orificing was added to the inlet plenum. Figure 44 shows the fuel temperatures before and after the flow orificing. The use of flow orificing increases the pressure drop across the core from 14 $\mathrm{kPa}$ to $73 \mathrm{kPa}$, with a corresponding increase in the pumping power from 1 to $5.5 \mathrm{MW}$; approximately $0.9 \%$ of the thermal power.

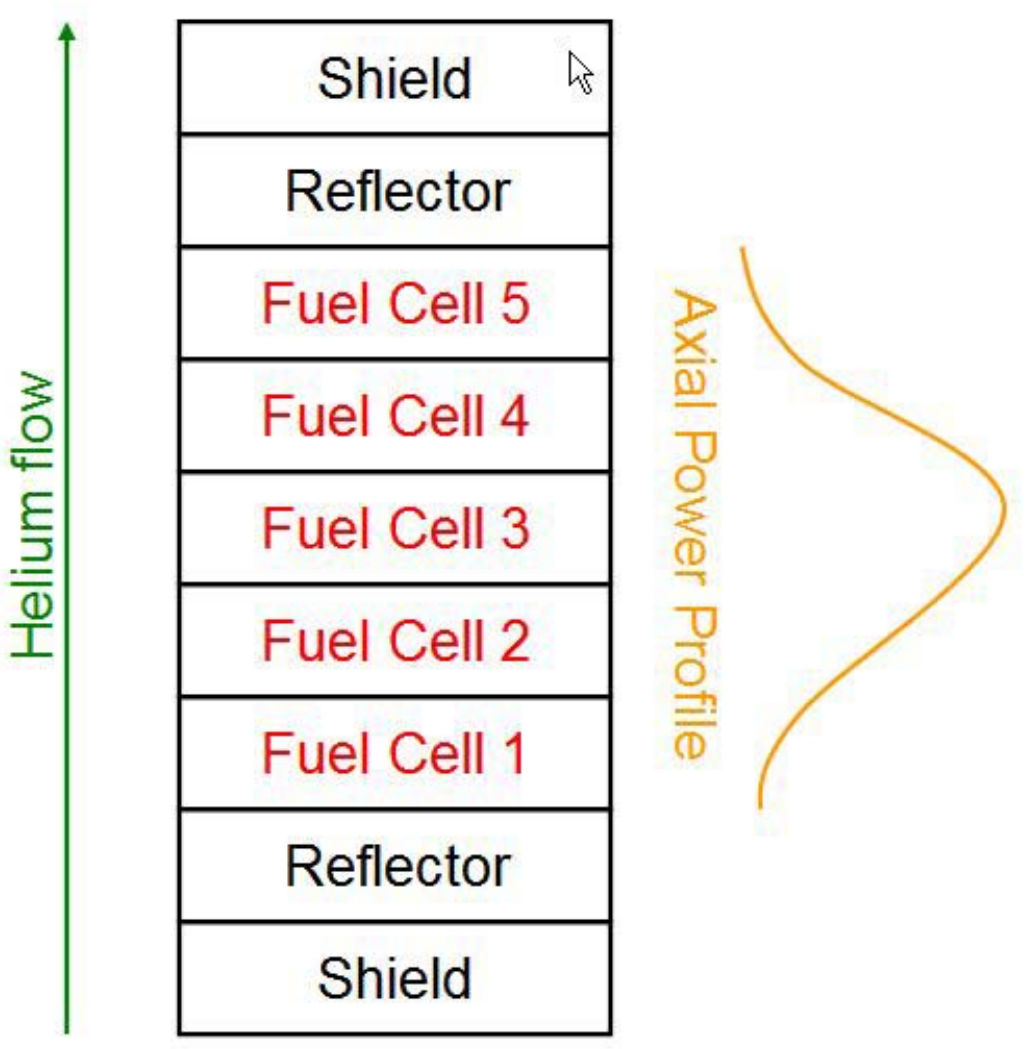

Figure 43: Axial cells of the fuel ring heat structure. 
Axial Temperature Distributions

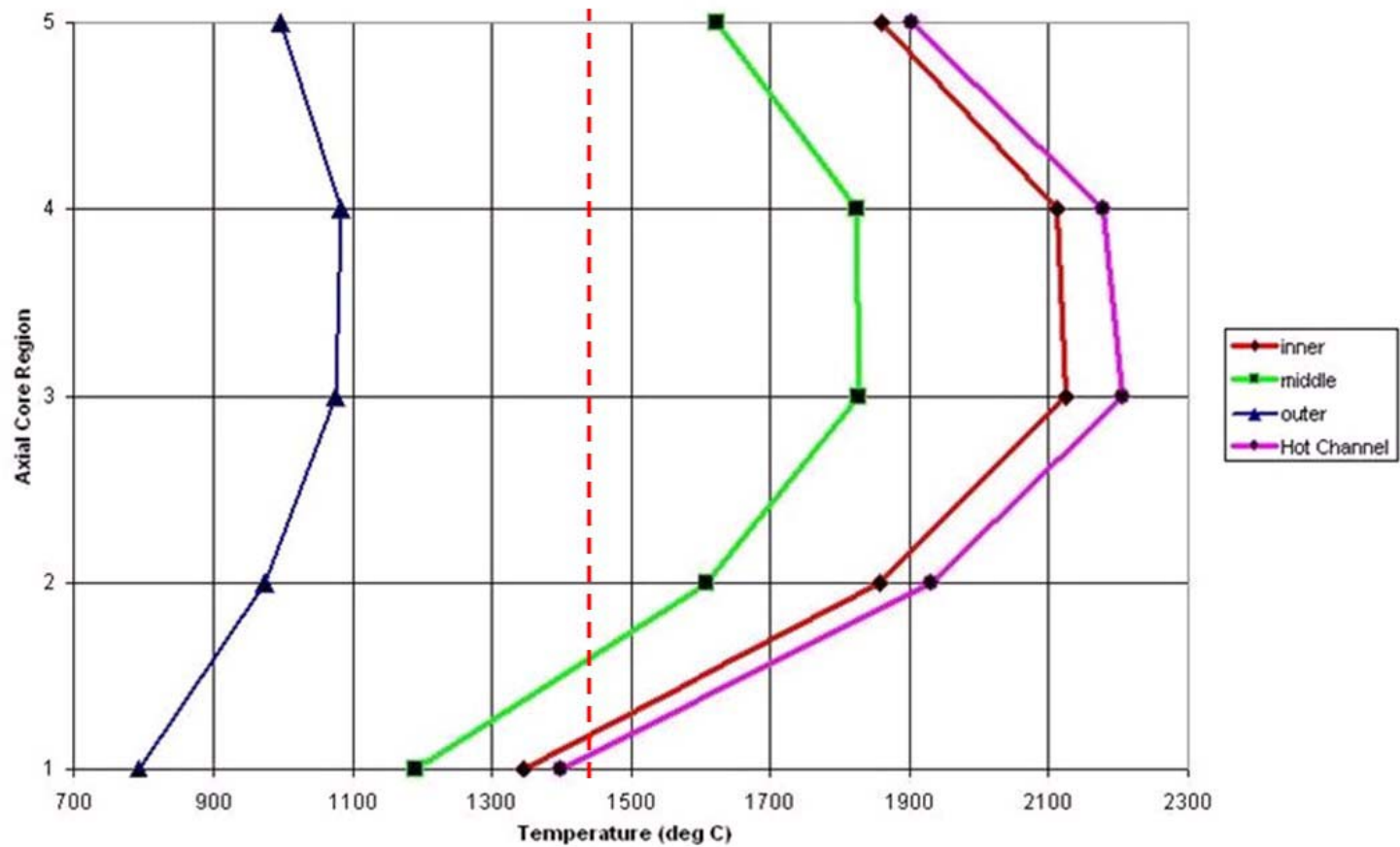

Figure 44: Fuel temperature with radial peaking - prior to inlet plenum orificing

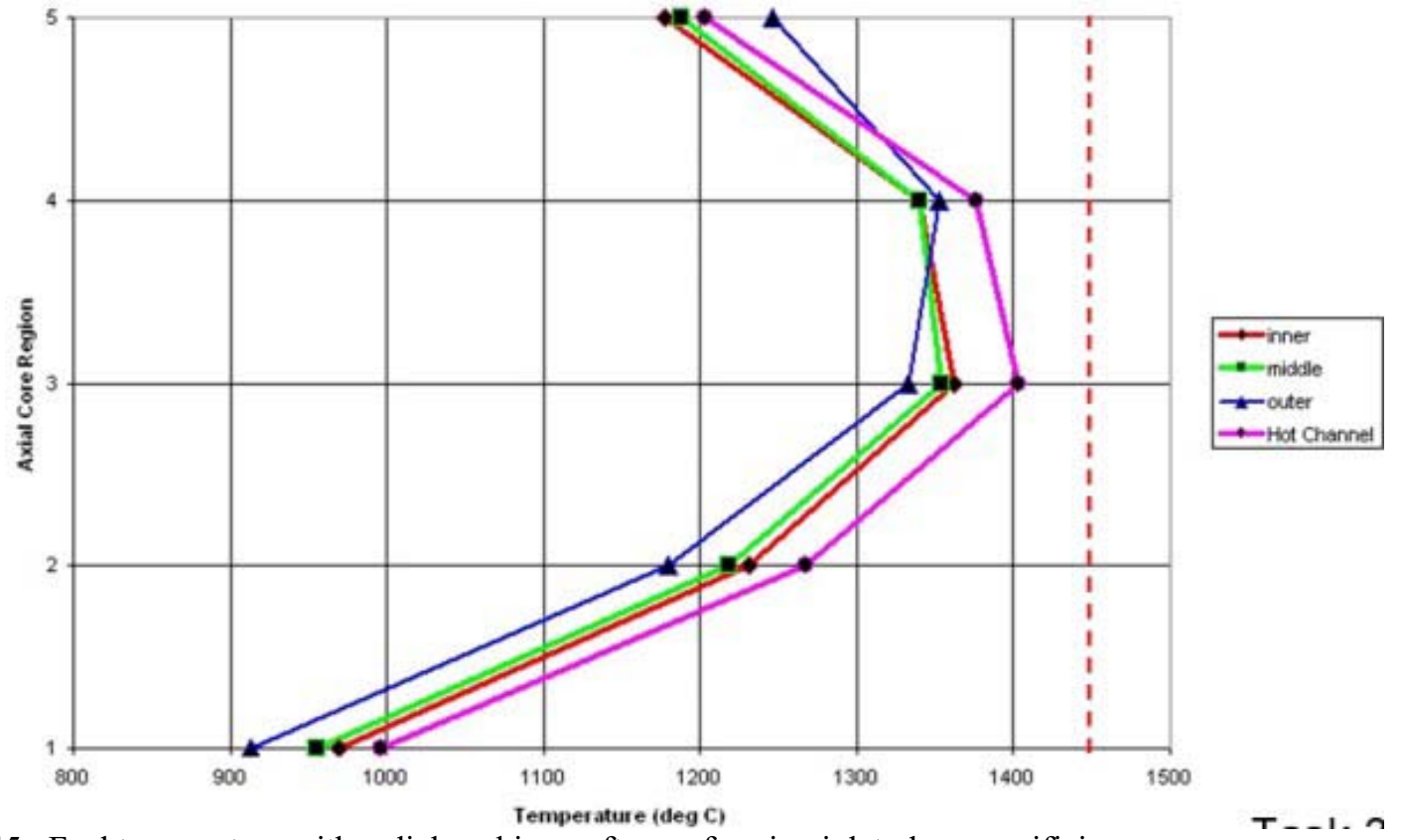

Figure 45: Fuel temperature with radial peaking - after performing inlet plenum orificing 


\subsubsection{SiC Thermal Conductivity Investigation}

A literature review suggested that $\mathrm{SiC}$ thermal conductivity decreases between one-third and one-half when the material is irradiated. Available data (Figure 46) imply that the change in thermal conductivity can increase the fuel temperature by as much as $150^{\circ} \mathrm{C}$, when the thermal conductivity is decreased by one-third. With the fast flux of approximately $10^{15} \mathrm{n} / \mathrm{cm}^{2}$-s, the loss of $\mathrm{SiC}$ thermal conductivity would occur within weeks of the reactor's operation. Analyses were initiated to examine the effects of $\mathrm{SiC}$ thermal conductivity on LOCA-induced fuel temperature and guard containment backpressure. However, these analyses were not completed prior to the NERI project's conclusion.

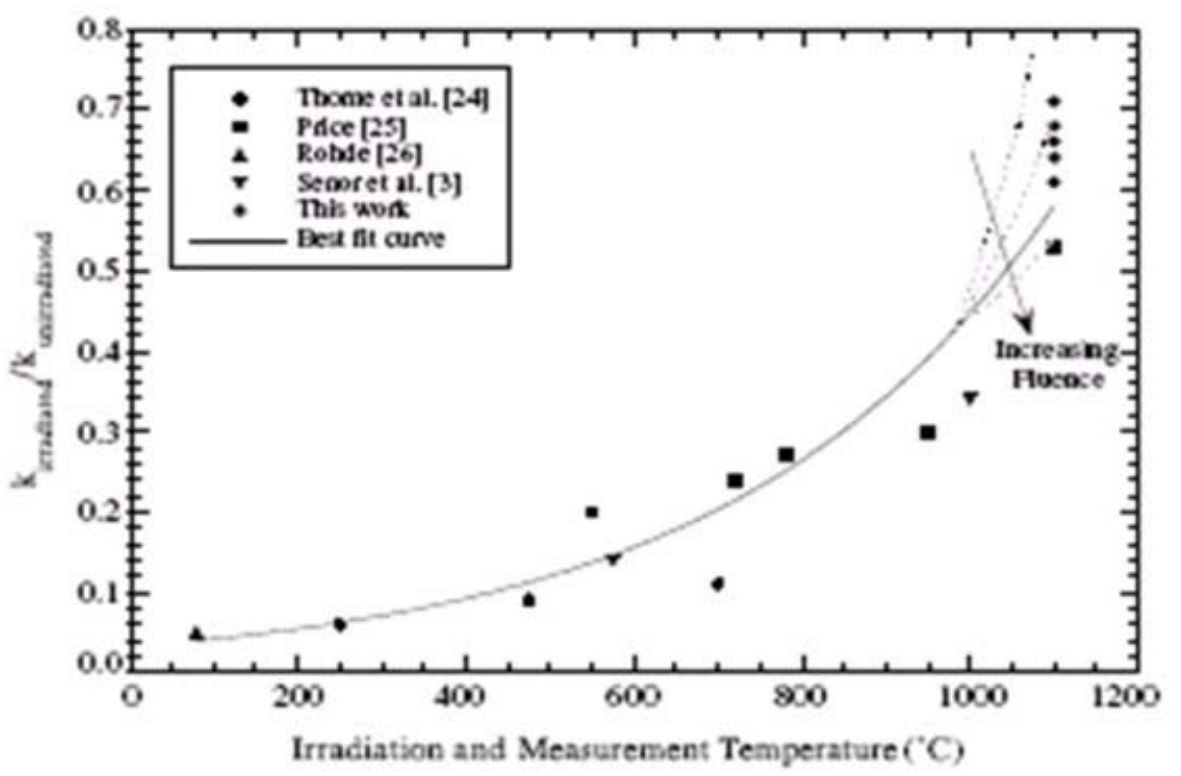

D.J. Senor et al. / Joumal of Nuclear Materials 317 (2003) 14S-159

Figure 46: $\mathrm{SiC}$ loss of thermal conductivity as a function of irradiation

\subsubsection{Containment - RCCS Interface Modeling}

A noticeable deficiency in the ATHENA LOCA analysis is the fact that ATHENA homogenizes the state values in a hydrodynamic volume. The consequence of this homogenization is that the convective heat transfer from the guard containment to the RCCS and the mixing of the reactor helium and the guard containment air are expected to be considerably underpredicted. An effort was initiated to create a Computational Fluid Dynamics (CFD) model of the reactor vessel, guard containment, and RCCS. The objective was that the CFD model would provide velocity profiles that could be input into ATHENA for the temperature calculations. This effort was approximately $20 \%$ complete with the NERI project concluded.

\subsection{Conclusions}

The principle objective of this research was to develop a realistic model of a prototypical gas fast reactor design and to use that model to examine the reactor's response during a simulated design basis accident. From the discussions presented, it is concluded that the current ATHENA model has considerably evolved beyond the simple hydrodynamic volumes and heat structure 
assemblies that are typical of initial design studies. Efforts were underway to increase the model's accuracy and correlation to reality.

The study of the LOCA scenario produced mixed results. It was observed that the design could survive the LOCA if there were sufficient backpressure in the guard containment. However, this survival is questioned when real world effects of irradiation, radial power profiling, and material thermal load limits are taken into consideration. On the other hand, it is realized that the current model underpredicts the convective heat transfer within the guard containment.

The general conclusion is that the current model provides a first order examination of the LOCA scenario. Improvements to the model in order to yield higher accuracy predictions were underway and need to be continued before it can conclusively be stated that the gas fast reactor design can completely survive a LOCA.

\section{References}

1 J. F. Briesmeister, .MCNPTM.A General Monte Carlo N-Particle Transport Code,. Los Alamos National Laboratory report LA-12625-M, Version 4B (March 1997).

2 R. L. Moore, B. G. Schnitzler, C. A. Wemple, R.S. Babcock, and D. E. Wessol, "MOCUP: MCNP-ORIGEN2 Coupled Utility Program," INEL-95/0523(September 1995).

3 A. G. Croff, .A User's Manual for ORIGEN2 Computer Code,. Oak Ridge National Laboratory report ORNL/TM-7175 (July 1980).

4 D. B. Pelowitz, ed., “MCNPX User's Manual Version 2.5.0,” Los Alamos National Laboratory report, in press (February 2005). 